\title{
Design, assembly, and characterization of membrane-spanning DNA nanopores
}

\author{
Conor Lanphere ${ }^{+}$, Daniel Offenbartl-Stiegert ${ }^{+}$, Adam Dorey, Genevieve Pugh, Elena \\ Georgiou, Yongzheng Xing, Jonathan R. Burns*, Stefan Howorka* \\ Department of Chemistry \& Institute of Structural Molecular Biology, \\ University College London, UK \\ *Corresponding author \\ ${ }^{+}$Authors contributing equally
}

EDITORIAL SUMMARY This protocol provides a detailed guide for the design and assembly of membrane-spanning DNA nanopores and includes assays for characterizing channel function.

TWEET A new protocol for design, assembly and characterisation of membrane-spanning DNA nanopores.

COVER TEASER Design and characterisation of DNA nanopores

Please indicate up to four primary research articles where the protocol has been used and/or developed.

1. T. Diederichs, G. Pugh, A. Dorey, Y. Xing, J. R. Burns, Q. H. Nguyen, M. Tornow, R. Tampé, S. Howorka, Nat. Comm., 2019, 10, 5018

2. J. R. Burns, A. Seifert, N. Fertig, S. Howorka, Nat. Nanotechnol., 2016, 11, 152-156

3. M. Langecker, V. Arnaut. T. G. Martin, J. List, S. Renner, M. Mayer, H. Dietz, F. C. Simmel, Science, 2012, 338, 932-936

4. J. R. Burns, E. Stulz, S. Howorka, Nano let., 2013, 13, 2351-2356

\begin{abstract}
DNA nanopores are bio-inspired nanostructures that control molecular transport across lipid bilayer membranes. DNA nanopores can be readily engineered in structure and function to synergistically combine the strengths of DNA nanotechnology and nanopores. The pores can be harnessed in a wide range of areas including biosensing, single-molecule chemistry and single-molecule biophysics, and in cell biology and synthetic biology. Here, we provide a protocol for the rational design of nanobarrel-like DNA pores and larger DNA origami nanopores for targeted applications. We discuss strategies for the pores' chemical modification with lipid anchors to insert into membranes, such as small unilamellar vesicles (SUVs) and planar lipid bilayers. The procedure covers the self-assembly of DNA nanopores via thermal annealing, their characterization using gel electrophoresis, purification, and direct visualization with transmission electron microscopy and atomic force microscopy. We also describe a gel
\end{abstract}


assay to determine pore-membrane binding and how transport through the pores is confirmed using single-channel current recordings and dye flux assays. We expect this protocol to take approximately one week to complete for DNA nanobarrel pores and 2-3 weeks for DNA origami pores.

\section{Introduction}

Nanopores are a class of structures that facilitate transport of molecular cargo across solid or semifluid membranes ${ }^{1-9}$. In biology, nanopores serve as molecular gate-keepers by selectively transporting genetic material, ions, and nutrients across cell membranes to help maintain cellular function ${ }^{10}$. Outside biology, membrane nanopores have been exploited for portable DNA sequencing ${ }^{11}$, biosensor ${ }^{4,9,12,13}$, or as model systems to study the physics of fluid transport ${ }^{9,14}$.

Biological protein nanopores can be engineered in structure and function for biorelevant applications. Prime examples are protein nanopores used for DNA sequencing ${ }^{11,15-17}$ where an atomically engineered inner lumen helps discern the DNA sequences from translocating strands. However, protein nanopores have limitations. For example their overall dimensions cannot be drastically changed and the de novo design is not easily achieved despite considerable progress ${ }^{18}$. This necessitates the use of other, more readily engineered materials, such as DNA, to fully harness the potential applications provided by nanopores.

Several research groups, including ours, have used DNA nanotechnology to develop various DNA nanopores with different dimensions and sensing capabilities. Examples include DNA pores made up of a single ${ }^{19}$, four ${ }^{20}$, or $\operatorname{six}^{21-27}$ DNA duplexes resulting in channel lumens of up to $2 \mathrm{~nm}$ in diameter. Larger structures with up to $9 \mathrm{~nm}$ channel diameters have also been created $^{21,28-31}$, along with a DNA cube that can function as a pore ${ }^{32}$. These DNA architectures mimic biological nanopores yet can allow easier design control over channel structure to target applications in biosensing, research, and synthetic biology.

Despite general interest in DNA nanopores, there is no unified and generic protocol that guides researchers through the process of designing, assembling and characterizing these nanostructures. For example, there are only partly overlapping protocols on the design and construction of a simple pore composed of a bundle of six interconnected DNA duplexes ${ }^{20,22-}$ ${ }^{24}$. Generic guidelines for designing six-duplex scaffolds have been published ${ }^{33,34}$, but these are not suitable for DNA pores as they do not account for lipid anchors required for membrane insertion. This is also true for most other DNA nanotechnology protocols which describe building the structures but not how to insert them into membranes using attached lipid anchors $^{35}$. Furthermore, several protocols for gel electrophoretic analysis of DNA pores diverge, as each pore differs in terms of its structural integrity but also its tendency to cluster due to the interacting hydrophobic lipid anchors ${ }^{36}$. Similarly, existing protocols for analyzing DNA nanostructures with atomic force microscopy (AFM) require adjustment for DNA nanopores to avoid higher-order assemblies that can form on the surface of AFM substrates ${ }^{22}$. Single-channel current recordings is the most commonly used technique to characterize ion transport through membrane-inserted pores, but this method is geared towards proteins nanopores ${ }^{15}$. Similarly, assays on fluorophore transport for protein pores needs to be adapted to the experimental conditions for DNA nanopores ${ }^{22,24,28}$. In our protocols, we aim to provide researchers with a reliable, unified procedure for all aspects of the design, assembly and characterization of DNA nanopores. 


\section{Comparison with other methods}

Membrane nanopores have been built with different construction materials including peptides, polymers, and organic molecules, each with their own strengths and weaknesses (Table 1$)^{14}$.

Table $1 \mid$ Comparison of nanopore construction materials. Adapted from ref ${ }^{14}$.

\begin{tabular}{|c|c|c|c|}
\hline Protein & Peptide & DNA & Synthetic organic \\
\hline $\begin{array}{l}+\quad \begin{array}{l}\text { Well defined and } \\
\text { stable structure }\end{array} \\
+\quad \begin{array}{l}\text { Precise engineering } \\
\text { via } \text { amino acid }\end{array} \\
\text { changes } \\
+\quad \text { Targeted addition of } \\
\text { synthetic } \\
\text { components } \\
-\quad \begin{array}{l}\text { Re or de novo design } \\
\text { difficult }\end{array} \\
-\quad \text { Few defined pores } \\
\text { with lumen wider } \\
\text { than }>5 \text { nm }\end{array}$ & 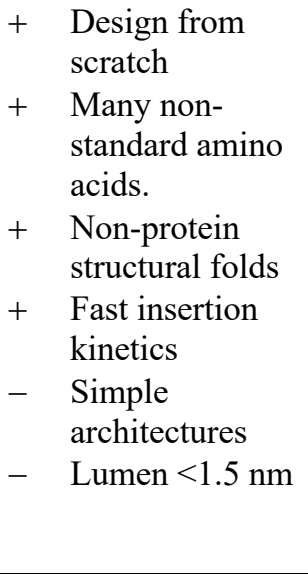 & $\begin{array}{ll}+ & \begin{array}{l}\text { Simple de novo } \\
\text { design }\end{array} \\
+ & \begin{array}{l}\text { Dedicated design } \\
\text { software }\end{array} \\
+ & \text { Structures }>20 \mathrm{~nm} \\
& \text { accessible } \\
-\quad & \text { Limited natural } \\
& \text { chemical repertoire } \\
- & \text { Structural } \\
& \text { fluctuations and } \\
\text { electronic } \\
\text { leakiness of walls } \\
-\quad \begin{array}{l}\text { Slow insertion } \\
\text { kinetics }\end{array}\end{array}$ & $\begin{array}{ll}+ & \text { Widest chemical } \\
& \text { repertoire } \\
+ & \text { Flexible design } \\
+ & \text { Compact sizes }<5 \\
& \text { nm } \\
- & \text { No unifying } \\
& \text { architectural } \\
& \text { principles } \\
- & \text { Challenging } \\
& \text { structural analysis } \\
- & \text { High } \\
\text { gating/closing } & \text { tendency }\end{array}$ \\
\hline
\end{tabular}

Constructing nanopores with DNA relies on the general advantages of this powerful building material that enables de novo design of nanostructures of almost any shape ${ }^{34,37-41}$. The success of DNA nanotechnology relies on highly predictable self-assembly from Watson-Crick base pairing. Consequently, DNA nanopore parameters can be customized readily, including pore diameter, height, wall thickness, and the site-controlled attachment of binding fragments for sensing, or controlled drug release $\mathrm{e}^{20-22,24,28-30,32}$. Furthermore, DNA nanopores are more easily folded than engineered protein pores and can have a more defined structure than organic nanopores ${ }^{14,42}$. In addition, chemical coupling to proteins can form functional hybrid materials ${ }^{43}$.

In order for DNA nanostructures to insert into lipid bilayers, hydrophobic groups must be incorporated to act as lipid anchors ${ }^{44}$. However, introducing hydrophobic anchors increases the synthesis complexity and can lead to aggregation of pores ${ }^{36,45-48}$. Other drawbacks are related to the structure's flexibility, and the permeability of the pore's walls to ions. Structural stability is desirable in sensing using protein nanopores to achieve high-quality read-out signals. However, synthetic organic pores with lower stability also perform well in analytical applications ${ }^{42}$. The structural stability of DNA nanopores can be enhanced by increasing the layers of DNA in the pore wall, and by increasing the interconnections between the duplexes within the nanostructure. The same route can be used to limit permeability through the DNA pore walls even though the ionic tightness of protein pores is difficult to match. Furthermore, the yield of DNA pore formation is usually in the nanomole to picomole range, which is sufficient for most, but not all applications. Finally, the cost of custom-synthesized DNA strands can be high when compared to biologically sourced scaffolds. To overcome this general shortcoming, approaches are being developed to produce staples by cells ${ }^{40,49}$.

\section{Application of the method}


Given the general interest in functional DNA nanostructures ${ }^{43,50,51}$, our protocol can help researchers create new functional transmembrane DNA pores to transport molecular cargo across membranes. These new membrane-spanning nanostructures could be used as biosensor units, as molecular shuttles and information relays in biomimetic vesicles, or as anchoring sites for designed receptors on cellular membranes. Reflecting the interdisciplinary nature of DNA nanopores, our protocol could be taken up by researchers in the fields of sensing, biophysics, nanotechnology, biomedicine, chemistry, and synthetic biology. Our protocol provides a stepby-step guide for designing, constructing, and characterizing DNA nanopores.

\section{Overview of the Procedure}

The procedure can be divided into several distinct stages as shown in a simplified workflow (Fig. 1). The initial stages are pore design, which includes its structure and lipid modification (steps 1-6), as well as assembly (step 7). After DNA pores have been created, the next step is to confirm their structural integrity using gel electrophoresis (step 8). Following initial assembly and structural confirmation, some structures require purification (steps 9-16). For directly visualizing DNA nanopores, transmission electron microscopy (TEM) (steps 17-26) and AFM (steps 27-40) can be used. The pores' membrane interaction and insertion can be probed with TEM and AFM, and a gel binding assay (steps 41-51). Finally, DNA pore function can be confirmed by single-channel current recordings (steps 52-72) and dye flux assays (steps 73-90).

\section{Experimental Design}

Expertise needed to implement the protocol. We expect this protocol to be used by graduate students with supervision. This protocol should enable researchers to undertake all stages involved from the design to the characterization of a novel DNA nanopore. Alternatively, individual sections can be used independently and applied to other pre-designed nanostructures.

Nanopore design (steps 1-6). Using DNA as a building material permits precisely tuned nanopore shape and nanoscale dimensions which are key parameters in pore function and application. There are two principle methods for designing DNA nanopores which were developed within the field of DNA nanotechnology prior to the advent of DNA nanopores. The first method - proposed by Nadrian Seeman in the $1980 \mathrm{~s}^{52,53}$ - can be adapted to selfassemble a nanobarrel-like structure with a hollow lumen from equimolar amounts of short DNA strands (see also Box 1). Reflecting the nanobarrels' small size and low structural complexity, the design can often be carried out solely by relying on Watson-Crick basepairing and the well-known geometry of DNA helices without the need for dedicated DNA design software. The nanobarrel design method can accommodate DNA oligonucleotides carrying lipid membrane anchors, fluorophores or bio-affinity tags to functionally enhance the pores. Exemplary outputs of this design method are pores composed of four ${ }^{20}$ and six interlinked helix bundles (4HB and 6HB) with channel lumen widths of around $2 \mathrm{~nm}^{22-26}$ (Fig. 2a). These simple nanobarrel DNA pores are comparable in size to protein pores but small in relation to other DNA nanostructures. To build larger or structurally more complex pores, another method has to be used.

To design large and structurally complex DNA nanopores ${ }^{21,28-30}$, the powerful and versatile 3D DNA origami route is ideal ${ }^{37,54,55}$ (see also Box 2, Fig. 2). Unlike the previous method, DNA 
origami relies on many more duplexes, which are arranged in either a hexagonal or squarelattice fashion. The core of the design is a long scaffold strand, which is folded with short staple strands into the desired architecture. These staple strands form inter-duplex crossovers that tie the structure together. Consequently, origami-type DNA pore's walls can be several DNA duplexes thick to provide structural support for a lumen considerably wider than for the nanobarrel-type pores ${ }^{37,54,55}$. For example, a wide lumen of $7.5 \mathrm{~nm} \times 7.5 \mathrm{~nm}$ in the DNA origami pore $72 \mathrm{HB}$ (Fig. 2a) can accommodate folded proteins for sensing applications ${ }^{30}$. The outer shape of DNA pores is also more complex than for simple barrel pores, as illustrated for a 54HB pore (Fig. 2a) ${ }^{21}$. Reflecting the use of generic DNA nanotechnology software, many of the design steps for the DNA origami pores are related to those for the design of other, nonpore origami structures ${ }^{56}$. The tested software tools increase design predictability for DNA pores. Drawbacks of DNA origami pores include a more involved design, longer folding times, and the higher cost of the component strands when compared to the simpler and smaller barreltype pores. Nevertheless, DNA origami pores feature numerous sites for attaching lipid anchors to facilitate nanopore insertion into membranes. Advantages and disadvantages of the two methods are summarized in Table 2.

Table 2 Comparison of two routes to design DNA nanopores

\begin{tabular}{|c|c|}
\hline DNA nanobarrel & DNA origami \\
\hline $\begin{array}{l}\text { Simple design, "by hand", ideal for } \\
\text { small pores }\end{array}$ & $\begin{array}{l}\text { cated design software } \\
\text { ages }\end{array}$ \\
\hline al functionalizati & omplex struc \\
\hline oligonucleotides & $+\quad$ Wide designed pore lumen enables \\
\hline $\begin{array}{l}+ \text { Fast folding, high yielding at } \mu \mathrm{M} \\
\text { concentrations }\end{array}$ & $\begin{array}{r}\text { transport of large molecular } \\
-\quad \text { Large number of staple stra }\end{array}$ \\
\hline ult to increase lumen diameter & affold strand costs \\
\hline $\begin{array}{l}\quad \text { beyond } \sim 3 \mathrm{~nm} \\
-\quad \text { Not suitable for complex architectures }\end{array}$ & $\begin{array}{l}\text { - Longer folding times } \\
\text { and purification of target structure }\end{array}$ \\
\hline
\end{tabular}

The design of a new DNA nanopore should be tailored to its intended function. One example is the $72 \mathrm{HB}$ pore $^{30}$ (Fig. 2a), which was designed for protein sensing. Consequently, the pore lumen was required to be sufficiently wide to accommodate folded proteins of up to $6 \mathrm{~nm}$ in size. The height of the nanopore was designed to be $40 \mathrm{~nm}$ to achieve longer protein transport times to facilitate analyte sensing. The elongated pore with 3-duplex thick-walls improved pore stability and led to a large extra-membrane cap region and a small transmembrane section (Fig $2 \mathrm{a})$. By contrast, the $6 \mathrm{HB}$ pore, with an inner lumen of $\sim 2 \mathrm{~nm}^{22}$, was designed to enable smallmolecule transport. The narrow lumen enables charge-selective small molecule transport ${ }^{22}$, the size-selective transport of peptides, but the rejection of larger folded proteins ${ }^{57}$. The $6 \mathrm{HB}$ is 9 $\mathrm{nm}$ high which is sufficient to span lipid bilayers.

In $72 \mathrm{HB}$ and $6 \mathrm{HB}$ pore designs, multiple DNA duplexes surround a central hollow lumen that spans the bilayer. In an alternative route, DNA pore behavior is achieved by a single duplex that forms small water-filled gaps between the duplex and the surrounding bilayer to enable ion transport. This has been demonstrated experimentally by modifying a single duplex with six porphyrin lipid anchors ${ }^{19}$.

Independent of design method, several types of hydrophobic anchors are available to insert negatively charged DNA pores into lipid bilayers (Fig. 2b). Cholesterol is the most commonly used lipid anchor and is usually attached in multiple copies around the pore perimeter. A single 
cholesterol is usually linked at the $3^{\prime}$ terminus of a component oligonucleotide ${ }^{20-22}$. Alternatively, commercially available DNA strands with a phosphorothioate (PPT) backbone can be alkylated to form hydrophobic alkylated-PPT ${ }^{58}$. Unlike the cholesterol anchor, the PPT approach can introduce multiple lipid anchors along each DNA strand within a pore ${ }^{23,59}$. Stretches of charge-masked DNA backbone can be arranged to form a hydrophobic belt. This lipid anchor belt form a tighter seal with the surrounding lipid bilayer (Fig 2c, Type I membrane interaction $)^{60,61}$ compared to cholesterol-based modifications that leave small water-filled gaps between the adjacent membrane (Fig. 2c, Type II) ${ }^{21}$. However, cholesterol modifications may lead to more frequent membrane binding. In addition, the commercial availability of cholesterol-modified oligonucleotides makes this lipid anchor time and cost effective.

Other anchors are also available, such as porphyrin ${ }^{19,47}$ or tocopherol ${ }^{29}$ that are covalently linked to the DNA pore. Porphyrins also exhibit strong fluorescence and can be used to visualize the nanopore directly. Another anchoring method uses the high-affinity biotinstreptavidin interaction to non-covalently link the DNA pore to biotin-modified-lipids ${ }^{29}$.

The lipid anchors position along the pore axis can also be controlled and fine-tuned (Fig. $2 \mathrm{~d})^{22,36,47}$. Terminally located anchors can lead to more rapid insertion, but should be positioned to ensure the pore completely spans the membrane.

In this protocol, we highlight the key principles to design two types of DNA nanopores: nanobarrel-type pores, as exemplified by the $6 \mathrm{HB}$ pore (Box 1, Fig. 4a) ${ }^{22}$, and DNA origamibased nanopores, which are designed using the open-source program CaDNAno (https://cadnano.org/), such as the $54 \mathrm{HB}^{21}$ and $72 \mathrm{HB}^{54}$. The DNA pores' thermal and structural stability can be simulated using software $\mathrm{CanDo}^{56,62}$ (https://cando-dna-origami.org. The simulations can serve as a quality control prior to ordering the component strands. The protocols provide guidance on the choice, positioning and number of lipid anchors for both nanobarrel and DNA origami pores. This includes commercially available cholesterolmodified DNA strands and the generation of in-house ethylated PPT strands. The procedures described in this section can be adapted to create related versions of existing pores, or applied to completely new pore designs.

Nanopore assembly (step 7). DNA nanopores require careful annealing procedures in order to successfully fold the desired structures. For small and simple DNA nanopores, such as the nanobarrel $6 \mathrm{HB}$ pore, folding occurs by a simple heating and cooling protocol, such as a single thermal annealing step ${ }^{22}$. DNA origami pores of bigger size and higher structural, or chemical complexity require more intricate annealing procedures ${ }^{21,30}$. In addition, the specific buffering conditions, including counter ions, can have a significant impact on the success of pore assembly. The buffering conditions should ideally be compatible with the intended downstream application to avoid the need for buffer exchange. The procedure in this protocol describes the annealing protocols and conditions for folding the $6 \mathrm{HB}^{22}$ and the $72 \mathrm{HB}$ pores ${ }^{30}$ and gives advice on how to develop a folding protocol for new designs and to minimize unwanted lipid-anchor interactions using mild detergents such as OPOE.

Gel electrophoretic characterization (step 8). Gel electrophoresis provides an efficient and quick method for determining successful DNA pore folding. The technique can also probe the successful incorporation of hydrophobic anchors. Both agarose gel electrophoresis and polyacrylamide gel electrophoresis (PAGE) can be used. The choice of gel type depends on the size of the pore. Agarose gel electrophoresis is the most versatile and can accommodate both nanobarrel and origami-based DNA structures. In comparison, PAGE provides better 
separation and analysis of smaller DNA pores. The percentage of the gels should be adapted to the size of the DNA nanopore to optimize their separation in both electrophoresis types. A gel running buffer containing detergent SDS can be added to avoid aggregation and gel smearing of DNA pores tagged with lipid anchors ${ }^{22}$.

Purification (step 9-16). Small DNA pores generally form in high yield, and therefore do not require purification. More complex, origami-based DNA pores need to be purified to remove excess staple strands. Four main methods are available to purify large DNA nanostructures. These are gel extraction ${ }^{63}$, precipitation by polyethylene glycol $(\mathrm{PEG})^{64}$, size exclusion chromatography (SEC) ${ }^{23,65}$, and ion exchange chromatography ${ }^{63,66}$. Each method is suited for a size range of DNA pores. The first three methods will be presented in our protocols ${ }^{63,66}$. Following purification, the concentration of the DNA nanopore must be ascertained.

Sample preparation for imaging with TEM (steps 17-26). TEM is a powerful tool to visualize DNA nanostructures ${ }^{51,67-69}$. The technique can be used to confirm DNA nanopores shape, size and channel lumen ${ }^{30}$. The membrane-bound state of the pores can also be characterized to establish expected behavior ${ }^{21,30}$. For TEM analysis, samples are typically subjected to negative staining prior to drying to remove excess dye and water. The procedure described in this protocol provides guidelines about how to prepare the samples of DNA nanopores in solution or inserted into membrane vesicles.

Sample preparation for imaging with AFM (steps 27-40). AFM is another versatile route to analyze DNA nanostructures ${ }^{37,70-74}$ and their interaction with lipid bilayers ${ }^{75,76}$. Staining is not required, and imaging can be conducted in liquid. For AFM analysis, DNA nanopores are deposited onto a mica support in salt-containing solutions ${ }^{22,23}$. Divalent metal cations ${ }^{77-79}$, or other cationic molecules ${ }^{80}$ tether the DNA nanostructures to the substrate. Adhered objects are then imaged by mapping the surface topography. AFM also allows the membrane binding properties of DNA nanopores to be studied using lipid bilayer-covered surfaces. For membrane insertion, DNA pores can be added directly onto lipid bilayer-coated mica, or alternatively, mixed with vesicles to be spread onto mica. For DNA nanopores with asymmetrical shapes, the membrane orientation can be elucidated. The procedure described in this protocol provides guidelines about how to prepare DNA pore samples for AFM analysis.

Gel assay to determine pore-membrane binding (steps 41-51). The interaction of lipidanchored DNA nanopores with bilayer membranes, such as small unilamellar vesicles (SUVs), can be quantitatively analyzed with agarose gels ${ }^{81}$. The interaction assay relies on the ability of gels to separate free DNA nanopores from membrane-bound pores. The latter pore-SUV complexes are too large to enter the gel meshwork. Using a gradient of increasing SUV concentration, the pore-membranes dissociation constant $\left(\mathrm{K}_{\mathrm{d}}\right)$ can be inferred ${ }^{25}$. This constant provides a simple means of comparing the membrane affinities of different DNA pores as a function of their size, lipid anchor, such as cholesterol, and lipid membrane type.

Single-channel current recordings (steps 52-72). Membrane-spanning pores facilitate transport across lipid bilayers. Perhaps the best route to determine transport is to measure flux of solvated ions through single DNA channels (see Box 3). Current measurements have determined several properties of DNA nanopores including their unitary pore conductance ${ }^{22-}$ 24,30 , their channel size using PEG molecules ${ }^{22,24}$, and their voltage-dependent conductance as a function of nanopore architecture ${ }^{22-24}$. The measurements also establish protein translocation $^{30}$ and triggered ion flux stemming from a nanomechanical DNA gate ${ }^{22}$. 
In single-channel conductance measurements, a lipid bilayer is formed over a small aperture that separates two chambers filled with electrolyte. Channel insertion is achieved by adding DNA nanopores mixed with a mild detergent to one of the chambers. Pore insertion is indicated by the characteristic increase in ionic current between the two chambers. The conductance largely stems from ion flow through the central pore lumen. The measured current may also include a small degree of current leakage through the gaps between the outside of the channel and the surrounding bilayer ${ }^{19,28}$. Successful insertion of DNA pores can also be obtained with electrophysiological equipment to measure multiple channels in parallel. The procedure in this protocol describes the use of the parallel recording equipment Orbit 16 (Nanion Technologies). This kit uses a disposable chip (MECA16, Ionera Technologies) featuring sixteen microcavities over which lipid bilayers can be formed and conductance measurements recorded ${ }^{22,30,82}$. The Orbit mini (Nanion Technologies) with a chip featuring four cavities can also be used and offers advantages such as temperature control $^{30}$.

Dye flux assays (steps 73-90). The transport properties of DNA pores can be further characterized by monitoring flux of fluorescent probes across pore-punctured membranes ${ }^{22,29,31}$. DNA nanopores have previously been shown to transport small-molecule fluorophores and discriminate between the dyes' size and charge ${ }^{22}$. Flux assays are versatile and rely on small dyes or fluorophore-labelled molecular cargo that crosses the membrane solely along the lumen of the DNA nanopore. In addition to dyes, transport can be determined with fluorescent proteins or polymers ${ }^{29,30}$. The procedure in this protocol describes the assay with model dye sulforhodamine B (SRB) that is encapsulated at high concentration inside SUVs to induce self-quenching properties. Addition of DNA pores and ensuing SRB flux into the main buffer solution reduces the dye's concentration and leads to a strong increase in fluorescence which can be recorded in kinetic traces.

MATERIALS

\section{REAGENTS}

Nanopore design (step 1)

- The sequences of DNA strands used to design the $6 \mathrm{HB}$ pore ${ }^{22}$ are provided in Supplementary Table 1.

\section{Introducing lipid anchors (step 6)}

- Cholesterol-modified DNA (IDT, ADTBio, Sigma Aldrich). The DNA sequences for $6 \mathrm{HB}^{22,48}$ are in Supplementary Table 1 and those for another six duplex barrel variant pore $^{47}$ are in Supplmentary Table 2. For the DNA sequences of the DNA origami pore $72 \mathrm{HB}^{30}$, see Supplementary Table 3.

- Phosphorothioate-modified DNA (custom DNA synthesis available from IDT DNA, HPLC-purified, ordered on 100-1000 nmol scale). For the sequences used to assemble the $6 \mathrm{HB}^{48}$ variant, see Supplementary Table 2.

- Dimethylformamide (DMF, Sigma-Aldrich, cat. no. D4551-250ML)

! CAUTION DMF is harmful to skin and toxic upon inhalation. It can also cause serious irritation to eyes. Only handle in a fume hood wearing gloves, a lab coat and eye protection.

- Tris-base (Sigma-Aldrich, UK, cat. no. T1503-25G)

- EDTA (Sigma-Aldrich, cat no. EDS-100G)

- SDS-PAGE running buffer (Sigma-Aldrich, cat. no. T7777-1L)

- Purple gel loading dye (New England Biolabs, UK, cat. no. B7024S) 
- Ethidium bromide solution (Sigma-Aldrich, cat. no. E1510-10ML)

! CAUTION Ethidium bromide is a suspected carcinogenic. Only handle in a fume hood wearing gloves, a lab coat and eye protection.

- Disposable scalpel (Fisher Scientific, cat. no. 12397999)

Nanopore assembly (step 7)

- Synthetic DNA (IDT DNA or Sigma Aldrich). The sequences of DNA strands used to assemble the $6 \mathrm{HB}^{22}$ and $72 \mathrm{HB}^{30}$ pores, see Supplementary Tables 1 and 3.

- HyClone HyPure Cell Culture Grade Water (GE Life Sciences, cat. no. SH30529.03)

- Phosphate Buffered Saline (Sigma-Aldrich, cat. no. P5493-1L)

- $\mathrm{MgCl}_{2} \bullet 6 \mathrm{H}_{2} \mathrm{O}$ (Sigma-Aldrich, CAS no. 7791-18-6)

- Tris-base (Sigma-Aldrich, UK, cat. no. T1503-25G)

- $\mathrm{KCl}$ (Sigma-Aldrich, CAS no. 7447-40-7)

- $\mathrm{NaCl}$ (Sigma-Aldrich, CAS no. 7647-14-5)

- OPOE (Enzo Life Sciences, CAS no. 27252-75-1)

Agarose gel electrophoretic characterization (step 8 Option A)

- UltraPure agarose (Invitrogen, Thermo Scientific, cat. no. 16500500)

- UltraPure 10x TAE buffer (Invitrogen, Thermo Scientific, cat. no. 15558026)

- Phosphate Buffered Saline (Sigma-Aldrich, cat. no. P5493-1L)

- $\mathrm{MgCl}_{2} \bullet 6 \mathrm{H}_{2} \mathrm{O}$ (Sigma-Aldrich, CAS no. 7791-18-6)

- $\mathrm{KCl}$ (Sigma-Aldrich, CAS no. 7447-40-7)

- Tris-base (Sigma-Aldrich, UK, cat. no. T1503-25G)

- DNA ladders (New England Biolabs, 100 base pairs, cat. no. N0467S; 1 kilo base pairs, cat. no. N0468S)

- Ethidium bromide (Sigma Aldrich, CAS no. 1239-45-8)

! CAUTION Ethidium bromide is a suspected carcinogenic. Only handle in a fume hood wearing gloves, a lab coat and eye protection.

- Gel loading dye, no SDS (New England Biolabs, cat. no. B7025S)

- Gel loading dye, SDS (New England Biolabs, B7021S)

- HyClone HyPure Cell Culture Grade Water (GE Life Sciences, cat. no. SH30529.03)

PAGE electrophoretic characterization (step 8 Option B)

- UltraPure 10x TBE buffer (Invitrogen, Thermo Scientific, cat. no. 15581044)

- 10x TGS buffer (Bio-Rad, cat. no. 1610732)

- Phosphate Buffered Saline (Sigma-Aldrich, cat. no. P5493-1L)

- $\mathrm{MgCl}_{2} \bullet 6 \mathrm{H}_{2} \mathrm{O}$ (Sigma-Aldrich, CAS no. 7791-18-6)

- $\mathrm{KCl}$ (Sigma-Aldrich, CAS no. 7447-40-7)

- Tris-base (Sigma-Aldrich, UK, cat. no. T1503-25G)

- DNA ladder (New England Biolabs, 100 base pairs, cat. no. N0467S)

- Ethidium bromide (Sigma Aldrich, CAS no. 1239-45-8)

! CAUTION Ethidium bromide is a suspected carcinogenic. Only handle in a fume hood wearing gloves, a lab coat and eye protection.

- Gel loading dye, no SDS (New England Biolabs, cat. no. B7025S)

- Gel loading dye, SDS (New England Biolabs, B7021S)

- HyClone HyPure Cell Culture Grade Water (GE Life Sciences, cat. no. SH30529.03)

Purification by gel extraction (Step 9 Option A)

- UltraPure agarose (Invitrogen, Thermo Scientific, cat. no. 16500500) 
- UltraPure TAE buffer 10x (Invitrogen, Thermo Scientific, cat. no. 15558026)

- $\mathrm{MgCl}_{2} \bullet 6 \mathrm{H}_{2} \mathrm{O}$ (Sigma-Aldrich, CAS no. 7791-18-6)

- DNA ladder (New England Biolabs, 1 kilo base pairs, cat. no. N0468S)

- Ethidium bromide (Sigma Aldrich, CAS no. 1239-45-8)

! CAUTION Ethidium bromide is a suspected carcinogenic. Only handle in a fume hood, whilst wearing gloves, a lab coat and eye protection.

- Gel loading dye, no SDS (New England Biolabs, cat. no. B7025S)

- HyClone HyPure Cell Culture Grade Water (GE Life Sciences, cat. no. SH30529.03)

\section{Purification by PEG precipitation (Step 9 Option B)}

- PEG 8000 (Sigma-Aldrich, CAS no. 25322-68-3)

- $\mathrm{NaCl}$ (Sigma-Aldrich, CAS no. 7647-14-5)

- UltraPure TAE buffer 10x (Invitrogen, Thermo Scientific, cat. no. 15558026)

- HyClone HyPure Cell Culture Grade Water (GE Life Sciences, cat. no. $\mathrm{SH} 30529.03$ )

Purification by size exclusion chromatography (Step 9 Option C)

- UltraPure TAE buffer 10x (Invitrogen, Thermo Scientific, cat. no. 15558026)

- HyClone HyPure Cell Culture Grade Water (GE Life Sciences, cat. no. $\mathrm{SH} 30529.03)$

- $\mathrm{MgCl}_{2} \bullet 6 \mathrm{H}_{2} \mathrm{O}$ (Sigma-Aldrich, CAS no. 7791-18-6)

- Ethanol (Sigma-Aldrich, absolute, for HPLC, $\geqslant 99.8 \%$, CAS no. 64-17-5)

$\triangle$ CRITICAL The purity of the organic solvent must be $>99 \%$ (i.e. HPLC or analytical grade)

Examining the concentration of DNA origami after purification (Steps 10-16)

- HyClone HyPure Cell Culture Grade Water (GE Life Sciences, cat. no. SH30529.03)

Sample preparation for imaging with transmission electron microscopy (TEM) (steps 17-26)

- DOPE (Avanti Polar Lipid, US, cat. no. 4004-05-1)

- DOPC (Avanti Polar Lipid, US, cat. no. 4235-95-4)

- Round bottom flask (Sigma-Aldrich, cat. no. Z723134-1EA)

- UltraPure TAE buffer 10x (Invitrogen, Thermo Scientific, cat. no. 15558026)

- $\mathrm{NaCl}$ (Sigma-Aldrich, CAS no. 7647-14-5)

- Chloroform (Sigma-Aldrich, CAS no. 67-66-3)

! CAUTION Chloroform is carcinogenic and highly toxic, and direct contact should be avoided. Only handle in a fume hood wearing gloves, a lab coat and eye protection.

$\triangle$ CRITICAL The purity of the chloroform must be $>99 \%$ (i.e. HPLC or analytical grade) to prevent contamination and lipid oxidation.

- Uranyl formate (Polysciences Inc, cat. no. 24762-1)

! CAUTION Uranyl formate is radioactive and should be used and disposed by following regulations of local department and related organization (like Euratom).

Sample preparation for imaging with atomic force microscopy (AFM) (steps 27-40)

- Mica (Agar Scientific, UK, cat. no. AGF7013)

- Metal specimen discs (Agar Scientific, UK, cat. no. AG16219)

- Glue (Fisher Scientific, UK, cat. no. 15602419)

- Cleaving tape (VWR, UK, cat. no. MMMAC60-ST)

- AFM-cantilevers (Bruker AFM Probes, CA, US, cat. no. MSNL-10) 
- $\mathrm{MgCl}_{2} \bullet 6 \mathrm{H}_{2} \mathrm{O}$ (Sigma-Aldrich, CAS no. 7791-18-6)

- DOPE (Avanti Polar Lipid, US, cat. no. 4004-05-1)

- DOPC (Avanti Polar Lipid, US, cat. no. 4235-95-4)

- Phosphate Buffered Saline (Sigma-Aldrich, cat. no. P5493-1L)

- $\mathrm{CaCl}_{2}$ (Sigma-Aldrich, UK, cat. no. C5670-100G)

Gel assay to determine pore-membrane binding (steps 41-51)

- UltraPure Agarose (Invitrogen, Thermo Scientific, cat. no. 16500500)

- UltraPure TAE buffer 10x (Invitrogen, Thermo Scientific, cat. no. 15558026)

- $\mathrm{KCl}$ (Sigma-Aldrich, CAS no. 7447-40-7)

- Tris-base (Sigma-Aldrich, UK, cat. no. T1503-25G)

- DNA ladder (New England Biolabs, 100 base pairs cat. no. N0467S, 1 kilo base pairs cat. no. N0468S)

- Ethidium bromide (Sigma Aldrich, CAS no. 1239-45-8)

! CAUTION Ethidium bromide is a suspected carcinogenic. Only handle in a fume hood wearing gloves, a lab coat and eye protection.

- Gel loading dye, no SDS (New England Biolabs, cat. no. B7025S)

- HyClone HyPure Cell Culture Grade Water (GE Life Sciences, cat. no. SH30529.03)

- POPC (Avanti Polar Lipids, powder, CAS no. 26853-31-6)

- Chloroform (Sigma-Aldrich, CAS no. 67-66-3)

! CAUTION Chloroform is carcinogenic and highly toxic, and direct contact should be avoided. Only handle in a fume hood wearing gloves, a lab coat and eye protection.

$\triangle$ CRITICAL The purity of the chloroform must be $>99 \%$ (i.e. HPLC or analytical grade) to prevent contamination and lipid oxidation.

Single-channel current recordings (steps 52-72 )

- $\mathrm{KCl}$ (Sigma-Aldrich, CAS no. 7447-40-7)

- KOH (Sigma-Aldrich, CAS no. 1350-58-3)

! CAUTION KOH is corrosive and can cause severe skin burns and eye damage. Only handle in a fume hood wearing gloves, a lab coat and eye protection.

- $\mathrm{HCl}$ (Sigma-Aldrich, CAS no. 7647-01-0)

! CAUTION HCl is corrosive and can cause severe skin burns and eye damage. Only handle in a fume hood wearing gloves, a lab coat and eye protection.

- HEPES (Thermo Scientific, cat. no. 15630106)

- DPhPC (Avanti Polar Lipids, powder, CAS no. 63-89-8)

- OPOE (Enzo Life Sciences, CAS no. 27252-75-1)

- Ethanol (Sigma-Aldrich, absolute, for HPLC, $\geqslant 99.8 \%$, CAS no. 64-17-5)

$\triangle$ CRITICAL The purity of the organic solvent must be $>99 \%$ (i.e. HPLC or analytical grade)

- Methanol (Fisher Scientific, CAS no. 67-56-1)

! CAUTION Methanol is toxic and can cause eye damage. Only handle in a fume hood wearing gloves, a lab coat and eye protection.

- $\triangle$ CRITICAL The purity of the organic solvent must be $>99 \%$ (i.e. HPLC or analytical grade) Isopropanol (Sigma-Aldrich, CAS no. 67-63-0)

! CAUTION Isopropanol can cause serious eye irritation as well as drowsiness. Only handle in a fume hood wearing gloves, a lab coat and eye protection.

- $\triangle$ CRITICAL The purity of the organic solvent must be $>99 \%$ (i.e. HPLC or analytical grade) Octane (Sigma-Aldrich, CAS no. 111-65-9) 


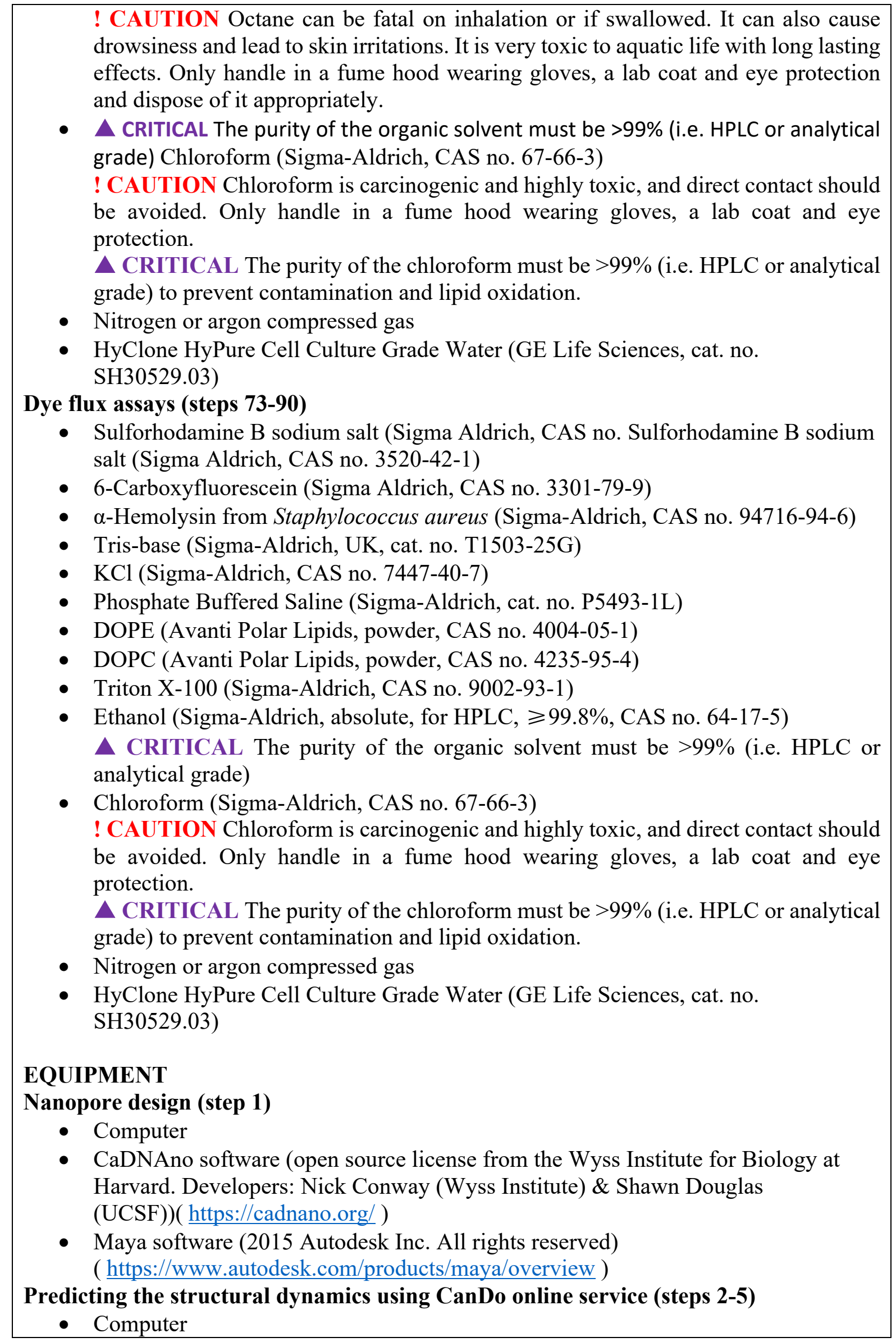


- CanDo software (developed at the Massachusetts Institute of Technology by Prof. Do-Nyun Kim (Seoul National University) while he was a postdoctoral research associate in the lab of Prof. Mark Bathe (MIT)) (https://cando-dna-origami.org/).

Introducing lipid anchors (step 6)

- Screw-top plastic vials (Fisher Scientific, UK, cat. no. 10350221)

- Gravity flow columns (GE Healthcare, illustra ${ }^{\mathrm{TM}}$ NAPTM Columns, NAP-25, cat.no. 17-0852-01)

- $\quad$ 4-20\% (wt/vol) gradient polyacrylamide gel (Bio Rad, cat. no. 4561096)

- Speed vacuum concentrator (Fisher Scientific, product no. 12884952)

- Thermomixer (Eppendorf, product no. 15158953)

- UV spectrophotometer (Varian, Cary 100 Bio, cat. no. EL00113097)

- Power pack (Bio-Rad, PowerPac ${ }^{\mathrm{TM}}$ Basic Power Supply, cat. no. 1645050)

- PAGE gel tank (Mini-PROTEAN Tetra Cell for Ready Gel Precast Gels, cat. no. 1658004EDU)

- Gel documentation system (Azure biosystems, product no. Azure c200)

- $1.5 \mathrm{~mL}$ Eppendorf tubes (Fisher Scientific, cat. no. 10051232)

- Electrospray ionization-ion trap mass spectrometry (MassLynx, Waters Corporation)

Nanopore assembly (step 7)

- Thermocycler (Bio-Rad, T100 ${ }^{\mathrm{TM}}$ Thermal Cycler, cat. no. 1861096)

- PCR tubes (Fisher Scientific, cat. no. AB1183)

- Pipettes (Gilson, PIPETMAN Classic Starter Kit, cat. no. F167300 and Gilson, PIPETMAN Classic P2 cat. no. F144801)

Agarose gel electrophoretic characterization (step 8 Option A)

- Power pack (Bio-Rad, PowerPac ${ }^{\mathrm{TM}}$ Basic Power Supply, cat. no. 1645050)

- Agarose gel tank (Bio-Rad, Wide Mini-Sub Cell GT Cell, cat. no. 1704468)

- Gel documentation system (Azure biosystems, product no. Azure c200)

- PCR tubes (Fisher Scientific, cat. no. AB1183)

- Fridge (Foster Refrigerator, model no. PREMG1350H)

- Pipettes (Gilson, PIPETMAN Classic Starter Kit, cat. no. F167300)

- Vortex mixer (VWR, UK, cat. no. 444-2790)

- $1.5 \mathrm{~mL}$ Eppendorf tubes (Fisher Scientific, cat. no. 10051232)

PAGE electrophoretic characterization (step 8 Option B)

- Mini-PROTEAN TGX Precast Gels (Bio-Rad, 10\%, 12-well comb, cat. no. 4561035)

- PAGE gel tank (Mini-PROTEAN Tetra Cell for Ready Gel Precast Gels, cat. no. 1658004EDU)

- Power pack (Bio-Rad, PowerPac ${ }^{\mathrm{TM}}$ Basic Power Supply, cat. no. 1645050)

- Gel documentation system (Azure biosystems, product no. Azure c200)

- PCR tubes (Fisher Scientific, cat. no. AB1183)

- Fridge (Foster Refrigerator, model no. PREMG1350H)

- Staining tray (Sigma-Aldrich, cat. no. T0567-4EA)

- Shaker (Heidolph, Titramax 100, cat. no. 544-11200-00)

- Pipettes (Gilson, PIPETMAN Classic Starter Kit, cat. no. F167300)

- Vortex mixer (VWR, UK, cat. no. 444-2790)

- $1.5 \mathrm{~mL}$ Eppendorf tubes (Fisher Scientific, cat. no. 10051232)

Purification by gel extraction (Step 9 Option A) 
- Agarose gel tank (Bio-Rad, Wide Mini-Sub Cell GT Cell, cat. no. 1704468)

- Gel documentation system (Azure biosystems, product no. Azure c200)

- Fridge (Foster Refrigerator, model no. PREMG1350H)

- $1.5 \mathrm{~mL}$ Eppendorf tubes (Fisher Scientific, cat. no. 10051232)

- Pipettes (Gilson, PIPETMAN Classic Starter Kit, cat. no. F167300)

- Disposable scalpels (Fisher Scientific, product code 11708353)

- Optical wipes (KIMTECH SCIENCE* Precision Wipes - White /Small)

- Glass microscope slides (VWR)

- Parafilm roll size 4 in. $\times 250 \mathrm{ft}\left(\right.$ PARAFILM $\left.{ }^{\circledR} \mathrm{M}\right)$.

Purification by PEG precipitation (Step 9 Option B)

- $\quad$ Pipettes (Gilson, PIPETMAN Classic Starter Kit, cat. no. F167300)

- Vortex mixer (American Scientific, S8223-1)

- Thermomixer (Eppendorf ThermoMixer Comfort, cat. no. 5382000031)

- $1.5 \mathrm{~mL}$ Eppendorf tubes (Fisher Scientific, cat. no. 10051232)

- Refrigerated centrifuge (Eppendorf, cat. no. 5415R)

Purification by size exclusion chromatography (Step 9 Option C)

- Pipettes (Gilson, PIPETMAN Classic Starter Kit, cat. no. F167300)

- Syringes (5 and $1 \mathrm{~mL})$

- 96-Well UV transparent plate (Corning, cat. no. CC791)

- Size exclusion chromatograph (GE Healthcare, ÄKTA purifier 100/10 fitted with a Superdex $75 \mathrm{~mL} \mathrm{10/300} \mathrm{GL} \mathrm{column)}$

- UNICORN 5.11 software (GE Healthcare)

Examining the concentration of DNA origami after purification (Step 10-16)

- Photometer (NanoDrop 8000 Spectrophotometer (V2.1.0))

- Optical wipes (KIMTECH SCIENCE* Precision Wipes - White /Small)

- Data processing software (NanoDrop 8000, ND-8000)

Sample preparation for imaging with TEM (steps 17-26)

- Glow-discharger (Quorum, SC7620)

- TEM grids (Agar Scientific, carbon film on 300 mesh copper grids, cat. no. AGS160-3H)

- TEM (Jeol, JEM-2100, equipped with an Orius SC200 camera)

- Vortex mixer (VWR, UK, cat. no. 444-2790)

- Vacuum pump (Buchi, cat. no. V-710)

- Heating bath (Buchi, cat. no. B-100)

- Rotary evaporator (Buchi, cat. no. R-100)

- $5 \mathrm{~mL}$ round bottom flask (VWR, cat. no. 201-8529)

- Centrifuge (Eppendorf, cat. no. 5415R)

- Parafilm (Fisher Scientific, cat. no. 10018130)

- $0.2 \mu \mathrm{m}$ syringe filter (Fisher Scientific, cat. no. 10776292)

- $15 \mathrm{~mL}$ Falcon tubes (Fisher Scientific, cat. no. 11507411)

- Extruder filters (Avanti Polar Lipids, Polycarbonate Membranes $0.1 \mu \mathrm{m} 19 \mathrm{~mm}$ (100/pk), cat. no. 610005)

- $1.5 \mathrm{~mL}$ Eppendorf tubes (Fisher Scientific, cat. no. 10051232)

- Glass slide (Fisher Scientific, cat. no. 12342108)

- Filtration paper (Fisher Scientific, cat. no. 11435248)

- Aluminum foil (Sigma-Aldrich, cat. no. Z185159)

- Gatan Microscopy Suite 3.0 
- Image processing software (ImageJ, Wayne Rasband, National Institutes of Health, USA) (https://imagej.nih.gov/ij/download.html)

Sample preparation for imaging with AFM (steps 27-40)

- Atomic force microscope (Bruker AXS, Multimode 8)

- Round bottom flask (Sigma-Aldrich, cat. no. Z723134-1EA)

- Plastic tweezers (Agar Scientific, cat. no. AGT5811)

- Fluid cell holder (Bruker AFM Probes, cat. no. MTFML-V2)

- Rotary evaporator (Buchi, $\mathrm{CH}$, cat. no. R-300)

- Bath sonicator (Grant instruments, cat. no. XUB25)

- Image processing software (Gwyddion, open source software, http://www.gwyddion.net/)

Gel assay to determine pore-membrane binding (steps 41-51)

- Dynamic light scattering equipment (Malvern, Zetasizer Nano S)

- Vacuum pump (Buchi, cat. no. V-710)

- Heating bath (Buchi, cat. no. B-100)

- Rotary evaporator (Buchi, cat. no. R-100)

- $5 \mathrm{~mL}$ round bottom flask (VWR, cat. no. 201-8529)

- Power pack (Bio-Rad, PowerPac ${ }^{\mathrm{TM}}$ Basic Power Supply, cat. no. 1645050)

- Agarose gel tank (Bio-Rad, Wide Mini-Sub Cell GT Cell, cat. no. 1704468)

- PAGE gel tank (Mini-PROTEAN Tetra Cell for Ready Gel Precast Gels, cat. no. 1658004EDU)

- Fridge (Foster Refrigerator, model no. PREMG1350H)

- Staining tray (Sigma-Aldrich, cat. no. T0567-4EA)

- Shaker (Heidolph, Titramax 100, cat. no. 544-11200-00)

- Pipettes (Gilson, PIPETMAN Classic Starter Kit, cat. no. F167300)

- Vortex mixer (VWR, UK, cat. no. 444-2790)

- SUV extruder (Avanti Polar Lipids, Extruder Set with Holder/Heating Block, cat. no. 610000)

- Extruder filters (Avanti Polar Lipids, Polycarbonate Membranes $0.1 \mu \mathrm{m} 19 \mathrm{~mm}$ (100/pk), cat. no. 610005)

- Bath sonicator (Grant instruments, cat. no. XUB25)

- Gravity flow columns (GE Healthcare, illustra ${ }^{\mathrm{TM}}$ NAPTM Columns, NAP-25, cat. no. 17-0852-01)

- Gel documentation system (Azure biosystems, product no. Azure c200)

- Image processing software (ImageJ, Wayne Rasband, National Institutes of Health, USA) (https://imagej.nih.gov/ij/download.html)

Single-channel current recordings (steps 52-72)

- $\mathrm{pH}$ meter (Fisher Scientific, product code 15534693)

- Single-channel current recording equipment (Nanion Technologies, Orbit 16)

- Single-channel current recording chips (Ionera Technologies GmbH, MECA16 Recording Chips $50 \mu \mathrm{m}$, order number 131002)

- Vortex mixer (VWR, UK, cat. no. 444-2790)

- $0.2 \mu \mathrm{m}$-filter (Corning, cat. no. 431229)

- Glass vials (Restek, cat. no. 21140)

- 1.5 mL Eppendorf tubes (Fisher Scientific, cat. no. 10051232)

- Pipettes (Gilson, PIPETMAN Classic Starter Kit, cat. no. F167300)

- Data analysis software (Elements srl, Elements Data Reader V3) (https://elementsic.com/edr-3-elements-data-reader-v3-2/) 
- Clampfit 10.7.0 (Molecular Devices) (https://moleculardevices.account.box.com/login )

\section{Dye flux assays (steps 73-90)}

- Vacuum pump (Buchi, cat. no. V-710)

- Heating bath (Buchi, cat. no. B-100)

- Rotary evaporator (Buchi, cat. no. R-100)

- pH meter (Fisher Scientific, 15534693)

- Vortex mixer (VWR, UK, cat. no. 444-2790)

- $5 \mathrm{~mL}$ round bottom flask (VWR, cat. no. 201-8529)

- Pipettes (Gilson, PIPETMAN Classic Starter Kit, cat. no. F167300)

- Gravity flow columns (GE Healthcare, illustra ${ }^{\mathrm{TM}}$ NAPTM Columns, NAP-25, cat.no. 17-0852-01)

- SUV extruder (Avanti Polar Lipids, Extruder Set with Holder/Heating Block, cat. no. 610000)

- Extruder filters (Avanti Polar Lipids, Polycarbonate Membranes $0.2 \mu \mathrm{m} 19 \mathrm{~mm}$ (100/pk), cat. no. 610006)

- Bath sonicator (Grant instruments, cat. no. XUB25)

- $1.5 \mathrm{~mL}$ Eppendorf tubes (Fisher Scientific, cat. no. 10051232)

- Fluorescence spectrophotometer (Agilent, Cary Eclipse Fluorescence Spectrophotometer, model no. EL06113020)

- Fluorescence cuvettes (Hellma Analytics, High Precision Cell, art. no. 105-250-1540)

\section{REAGENT SETUP}

Buffer 1: $30 \mathrm{mM}$ Tris, $\mathrm{pH}$ 8.0. This buffer can be stored at room temperature (RT: 20$25^{\circ} \mathrm{C}$ ) for up to 3 months.

Buffer 2: TGS (25 mM Tris, $192 \mathrm{mM}$ glycine, 0.1\% (w/v) SDS, pH 8.3). The 1x buffer should be replenished after every 3 gels. The 10x stock can be stored at RT for up to 2 years.

Buffer 3: TAE (40 mM Tris, $20 \mathrm{mM}$ acetic acid, $\mathrm{pH} 8.3$ ), supplemented with 0-20 mM $\mathrm{MgCl}_{2}$. This buffer can be stored at RT for up to 3 months, but if used for gels, it should be replenished after every 3 gels. The $10 \mathrm{x}$ stock can be stored at RT for up to 2 years.

Buffer 4: PBS (137 mM NaCl, $2.7 \mathrm{mM} \mathrm{KCl}, 10 \mathrm{mM} \mathrm{Na}_{2} \mathrm{HPO}_{4}, 1.8 \mathrm{mM} \mathrm{KH}_{2} \mathrm{PO}_{4}, \mathrm{pH}$ 7.4). This buffer can be stored at RT for up to 3 months. The 10x stock can be stored at RT for up to 2 years.

Buffer 5: $0.3 \mathrm{M} \mathrm{KCl}, 15 \mathrm{mM}$ Tris-HCl, $\mathrm{pH}$ 7.4. This buffer can be stored at RT for up to 3 months. The 10x stock can be stored at RT for up to 2 years.

Buffer 6: TBE ( $89 \mathrm{mM}$ Tris-borate, $2 \mathrm{mM}$ EDTA, $\mathrm{pH} 8.3$ ). The $1 \mathrm{x}$ buffer should be replenished after every 3 gels. The 10x stock can be stored at RT for up to 2 years.

Buffer 7: TAE (40 mM Tris, $20 \mathrm{mM}$ acetic acid, $\mathrm{pH} 8.3$ ), supplemented with $0.5 \mathrm{M} \mathrm{NaCl}$. This buffer can be stored at RT for up to 3 months.

Buffer 8: TAE (40 mM Tris, $20 \mathrm{mM}$ acetic acid, $\mathrm{pH} 8.3$ ), supplemented with $0.5 \mathrm{M} \mathrm{NaCl}$ and $15 \%$ PEG-8000 (w/v). This buffer can be stored at RT for up to 3 months.

Buffer 9: PBS (137 mM NaCl, $2.7 \mathrm{mM} \mathrm{KCl}, 10 \mathrm{mM} \mathrm{Na}_{2} \mathrm{HPO}_{4}, 1.8 \mathrm{mM} \mathrm{KH}_{2} \mathrm{PO}_{4}, \mathrm{pH}$ 7.4), supplemented with $10 \mathrm{mM} \mathrm{CaCl}_{2}$. This buffer can be stored at RT for up to 3 months. A $10 \mathrm{x}$ stock can be stored at RT for up to 2 years.

Buffer 10: $1 \mathrm{M} \mathrm{KCl}, 10 \mathrm{mM}$ HEPES, $\mathrm{pH}$ 7.4. This buffer can be stored at RT for up to 3 months. 
Buffer 11: PBS (137 mM NaCl, $2.7 \mathrm{mM} \mathrm{KCl,} 10 \mathrm{mM} \mathrm{Na}_{2} \mathrm{HPO}_{4}, 1.8 \mathrm{mM} \mathrm{KH}_{2} \mathrm{PO}_{4}, \mathrm{pH}$ 7.4), supplemented with $50 \mathrm{mM}$ sulforhodamine B. This buffer can be stored at RT for up to 3 months but must be shielded from light.

\section{Lipid stocks}

Order lipids as a powder (solid) and dissolve in dry chloroform to a final concentration of $10 \mathrm{mM}$ in small glass vials with Teflon sealing caps. Then, seal with Parafilm and store at $20{ }^{\circ} \mathrm{C}$.

$\triangle$ CRITICAL Store lipid solutions for up to 2 weeks at $-20^{\circ} \mathrm{C}$ to prevent lipid oxidation. $5 \mathrm{M} \mathrm{NaOH}$ solution for TEM

Store at $-20^{\circ} \mathrm{C}$ for up to 3 months.

$2 \%$ (wt/vol) Uranyl formate stock solution

Boil $30 \mathrm{~mL} \mathrm{H}_{2} \mathrm{O}$ in a $200 \mathrm{~mL}$ beaker for 2-3 min to de-oxygenate the water. Weigh out 0.1 $\mathrm{g}$ of uranyl formate in a $15 \mathrm{~mL}$ falcon tube, then add $5 \mathrm{~mL}$ of boiled $\mathrm{H}_{2} \mathrm{O}$. Tightly close the lid and wrap the tube in aluminum foil. Vortex vigorously for $10 \mathrm{~min}$. Filter the solution using a $0.22 \mu \mathrm{m}$ syringe filter into a new falcon tube. Then, aliquot each $200 \mu \mathrm{L}$ of solution into a $1.5 \mathrm{~mL}$ plastic tube. Wrap these in aluminum foil and store at $-20{ }^{\circ} \mathrm{C}$ for up to 6 months.

\section{Fresh $2 \%$ (wt/vol) Uranyl formate staining solution}

Thaw one aliquot of the $2 \%(\mathrm{wt} / \mathrm{vol})$ uranyl formate stock solution, then add $1 \mu \mathrm{L}$ of $5 \mathrm{M}$ $\mathrm{NaOH}$ to the tube. Vortex immediately for 2-3 min. Centrifuge the solution at max speed for 3 min and wrap in aluminum foil. This should be made fresh before each use.

\section{Lipid solution for planar lipid bilayers}

Allow the lipid stock to reach ambient temperature then aliquot in $1 \mathrm{mg}$ (equivalent) of DPhPC lipid into a glass vial. Evaporate the chloroform from the glass vial using a gentle, steady stream of nitrogen gas. A thin film of lipid will be visible on the wall of the glass vial. Dissolve the lipid film in $100 \mu \mathrm{L}$ of dry octane. and vortex briefly to ensure the lipid film is fully dissolved, giving a final concentration of $10 \mathrm{mg} \mathrm{mL}^{-1} \mathrm{DPhPC}$ in octane.

$\triangle$ CRITICAL Lipid quality is crucial for stable lipid bilayers. Use the highest-grade solvents and prepare fresh lipid solution in octane to be used for bilayer formation on a weekly basis.

$\triangle$ CRITICAL It is important to allow the lipid stock solution to warm up to ambient temperature before opening to container to prevent condensation inside the container. Condensation can lead to lipid oxidation.

\section{EQUIPMENT SET-UP}

Extruder

Assemble the extruder according to the manufacturer's instructions.

$\triangle$ CRITICAL The extruder must be cleaned after every use.

- Fluorescence spectrophotometer For analysis of pore flux using the sulforhodamine B fluorophore.

Scan mode: Set the excitation wavelength to $565 \mathrm{~nm}$, the emission range to $570-620 \mathrm{~nm}$, the excitation and emission slit width to $5 \mathrm{~nm}$, and the power to $600 \mathrm{~V}$.

Kinetics mode: Set the excitation wavelength to $565 \mathrm{~nm}$, the emission wavelength to 586 $\mathrm{nm}$, the excitation and emission slit width to $5 \mathrm{~nm}$, the power to $600 \mathrm{~V}$. The collection time should be set up to $65 \mathrm{~min}$, the collection rate at 1 data point per s, and mixing on (if applicable), and all data should be saved as ASCII format.

- For analysis of flux using the carboxyfluorescein fluorophore.

Scan mode: Set the excitation wavelength to $495 \mathrm{~nm}$, the emission range to 505-549 nm, the excitation and emission slit width to $5 \mathrm{~nm}$, and the power to $600 \mathrm{~V}$. 
Kinetics mode: Set the excitation wavelength to $495 \mathrm{~nm}$ and the emission wavelength to

$517 \mathrm{~nm}$. All other settings are the same as for sulforhodamine B.

\title{
PROCEDURE
}

\section{Nanopore design}

1. To design DNA nanopores using the nanobarrel method, follow Option A (see also Box 1). To design DNA nanopores using the DNA origami route, follow Option B (see also Box 2). The nanobarrel method is ideal for small, relatively simple DNA nanopores, such as the 6HB (Fig. 3a-c, Box 1 Fig. 4a), while DNA origami is best suited for large and complex DNA nanopores (Fig. 3d-f).

\section{Option A: Nanopore designs using the nanobarrel method - TIMIING $1-3 \mathrm{~d}$}

\begin{abstract}
Box 1: Nanobarrel pore designs
Nanobarrel-type DNA pores are small, versatile and relatively simple to design and build. They are comparable in size to protein pores and mimic only the transmembrane stem. Once inserted, the membrane can increase the pores' stability, which together with their small size alleviates the need for multiple layers of DNA duplexes. These parameters simplify the design process and can be conducted by hand, even though specialist software such as $\mathrm{CaDNAno}^{54,67}$ and Perdix ${ }^{83}$ may also be used. Other key benefits of nanobarrel-type pores include cheaper component DNA costs, readily accessible higher concentrations, and the ease of incorporating lipid anchors in every component strand. The designs of nanobarreltype pores vary in the position and number of crossovers between duplexes, including terminal , single and double Fig. 4 crossovers (Fig.4a-c, respectively). The wireframe design (Fig. 4d) yields pores of cube-shape.
\end{abstract}

\section{Terminal Crossovers}

The design uses duplexes which are linked at the top and bottom using terminal crossovers. The barrel does not contain any internal crossovers which may introduce flexibility between duplexes. However, the lack of internal crossovers can be used to readily control the position of chemical modifications within the duplex. Terminal modifications located at the 5 ' and $3^{\prime}$ DNA termini can be easily moved by adjusting the nick position along the duplex. The barrel diameter can be adjusted by adding or removing duplexes. In addition, the duplexes can be elongated to form part of a nanovalve for controlled channel opening triggered by $\mathrm{DNA}^{22}$ or temperature ${ }^{81}$.

\section{Single Crossovers}

In this pore type, the duplexes are connected using single crossovers to unify the structure. Crossovers occur throughout the design giving more structural rigidity between duplexes. The framework can be extended to increase the length of the pore's height and diameter. The tile design of this type of barrel allows for rapid folding. 
The double crossover barrel design is based on DNA origami assembly junctions found in the honeycomb lattice (see Box 2). Crossovers can occur at $7 \mathrm{bp}$ intervals between duplexes throughout the structure. The highly interwoven lattice helps aid structural stability of the barrel.

\section{Wireframe}

The wireframe enables distinct geometric shapes to be developed. The hollow structure of the barrel can result in a high degree of flexibility. However, the structures' dimensions can be fine-tuned by extending or reducing the duplex length at each edge. In addition, binding motifs can be incorporated into the design at protruding edges ${ }^{84}$.

(i) Generate a strand map on a piece of graph paper by drawing six duplexes next to each other. Each square in the graph paper can represent a base. The duplexes should be drawn as two anti-parallel lines.

(ii) Determine the length of the duplexes and adjust them to span lipid bilayers.

CRITICAL STEP Lipid bilayers are $~ 3.4 \mathrm{~nm}$ thick, whilst the hydrophobic core measures $\sim 2.2 \mathrm{~nm}$, this corresponds to 9 and $6 \mathrm{bp}$ in length, respectively. In the $6 \mathrm{HB}$ barrel design the duplexes are 21 bp long, which means that $\sim 6$ bp protrude at either side of the lipid bilayer.

(iii) Identify the simplest means of connecting the duplexes. Connect the duplexes together at the top and bottom with short loops of 4 nucleotides to form a unified helical bundle. Each duplex should be $21 \mathrm{bp}$ (two full helical turns) long to ensure the loops come in and out at the same angle ${ }^{21,27}$. In the case of the $6 \mathrm{HB}$ nanobarrel, helices are hexagonally arranged, giving rise to an interior angle of $120^{\circ}$ between duplexes. To make smaller or larger helical bundles, subtract or add duplexes.

CRITICAL STEP Thymine mismatches can be included at the hairpin loops to prevent intermolecular blunt-end stacking interactions.

(iv) Determine the positions of the DNA termini. The location of the DNA 5' and 3' phosphate within the DNA duplexes will dictate the position of any terminal modifications, including lipid anchors and fluorescent dyes.

CRITICAL STEP The strands' termini cannot be within the loops as this would compromise successful folding. The nicks should be placed at least $7 \mathrm{bp}$ from the loops.

(v) Generate the DNA sequences of each duplex by adding the bases to each square of the graph paper for the duplex ${ }^{22}$. Each base must be complementary to the other base in the duplex except the bases in the single strand loops.

(vi) Validate the sequences for complementarity using the oligo analyzer tool on the IDT website (https://idtdna.com/calc/analyzer), or NUPAK software (http://www.nupack.org/). The software can also identify any unwanted hairpins or heterodimers and the influence of different salts and oligonucleotide concentrations on duplex stability.

CRITICAL STEP Hairpins and DNA strands binding to non-target DNA sequences should have a $\Delta \mathrm{G}$ with a magnitude lower than $-8 \mathrm{kcal}^{\mathrm{mol}}{ }^{-1}$. Typical $\Delta \mathrm{G}$ values of the targeted binding sections range from -35 to $-42 \mathrm{kcal}^{\mathrm{mol}}{ }^{-1}$ (IDT oligoanalyzer tool: https://idtdna.com/calc/analyzer for the $6 \mathrm{HB}$ pore $^{22}$. The exact value will depend on the 
length of the strands, the sequences, the location of crossovers and the buffering conditions. Exemplary results are shown for 6HB in Fig. 3c.

CRITICAL STEP In case of difficulties with manually designing the duplexes, software CaDNAno can be used to design the pore and obtain the sequences of component DNA strands (see Step 1B).

(vii) (Optional) Check the structural dynamics of the nanopore using the online service CanDo (steps 2-4).

(viii) Procure the oligonucleotides (see step 5).

Option B: Nanopore design using DNA origami - TIIMING 1-7 d, depending on the complexity of the structures.

\begin{abstract}
Box 2: Using CaDNAno to design DNA origami nanopores
CaDNAno enables nanostructures to be built with a simple set of design rules using a reduced representation of DNA. DNA origami structures are usually constructed from a long scaffold strand which is held in place by hundreds of staples strands. The scaffold strand is routed through adjacent helices to develop a scaffold version of the nanostructure. The short staple strands hybridize to target sections of the scaffold to generate the desired nanostructure. Crossovers between adjacent duplexes can only take place where the helical backbones are at their closest points of contact. In the B-form of DNA each bp is rotated by $34.3^{\circ}$. This rotation enables two types of networks to be engineered, the honeycomb and square lattices.
\end{abstract}

\title{
Honeycomb lattice
}

The honeycomb lattice enables each duplex to interconnect to three neighboring helices (Fig. 5a). Crossovers can occur every $7 \mathrm{bp}\left(240^{\circ}\right)$ when the adjacent duplexes align. This corresponds to a rotation of $34.2^{\circ}$ per bp which is similar to the native form. Due to the less densely packed nature of the lattice framework, nanopore designs can be more permeable to ions than square-lattice versions. For further explanations on this DNA origami lattice, consult tutorial videos for CaDNAno (https://www.youtube.com/user/cadnano).

\section{Square lattice}

In the square lattice each duplex can connect to four neighboring helices (Fig. 5b). Crossovers can occur every $8 \mathrm{bp}\left(270^{\circ}\right)$ when the adjacent duplexes align. This corresponds to a rotation of $33.8^{\circ}$ per bp which induces a slight underwinding of the duplex from its native form. This underwinding can induce a small global twist in the nanostructure, however this can be corrected by introducing mis-matches into the sequence ${ }^{55,56}$. The square lattice network enables densely packed nanostructures to be generated which can be useful for generating more robust pore walls ${ }^{30}$.

\section{Using CaDNAno}

CaDNAno's program interface contains two panels, a "Slice Panel" and a "Path Panel" (Fig. 5). The slice panel shows a bird's eye view of the DNA helices. Each helix is represented as a circle. The path panel displays a 2D map of the scaffold and staple strands' path. In this panel, each helix is represented by two rows of squares (light gray). Each row represents either the scaffold or staple strand, whilst each square represents a single base. The top row of bases runs in the $5^{\prime} \rightarrow 3^{\prime}$ direction, and the bottom row runs from $3^{\prime} \rightarrow 5^{\prime}$. The $5^{\prime}$ phosphate termini are represented as squares, whilst the $3^{\prime}$ termini are represented as triangles. In the 
honeycomb lattice the bases are grouped in sets of seven, whilst in the square lattice the bases are grouped in sets of eight. The orange slice bar in the "Path Panel" links the selected location to the corresponding view in the slice panel. This can be moved to display the crosssection (slice) at any point along the duplexes of the DNA nanopore.

A third "Render Panel" can be utilized when CaDNAno is used as a plug-in for Maya 2015. This panel shows a 3D representation of the DNA nanostructure where each duplex is represented as a cylinder (Fig. 6).

(i) Pore design (Steps i-iii). Conceive the shape, dimensions and lattice-type of the DNA origami nanopore. It may be helpful to hand-draw a sketch of the proposed nanopore design to scale. Determine if the duplexes should be aligned parallel or perpendicular to the membrane such as in the 52HB pore (Fig. 2a) ${ }^{21}$

CRITICAL STEP The choice of lattice type should be considered carefully as it can determine the size and structure of the design and influence the lipid anchors' positioning.

(ii) Install and run CaDNAno (https://cadnano.org/) on your computer. It is recommended to also install Maya 2015 (https://www.autodesk.com/products/maya/overview) to support $3 \mathrm{D}$ rendering.

(iii) In the "Slice Panel" in CaDNAno all the possible duplexes are represented by gray circles. The duplexes are activated by double-clicking (Fig. 7a) on the desired circles. This changes the color to orange and generates a duplex number. The activated duplexes now appear in the "Path Panel".

(iv) Pore design - scaffold routing (steps iv-v). Use the "Pencil" tool in the "Path Panel" to extend the scaffold strands to the desired lengths (Fig. 7a).

(v) Link the separate scaffold strands via crossovers. To do so, click on a strand to show the possible crossovers positions as indicated by the blue brackets (Fig. 7a). A crossover can be generated by clicking on the chosen bracket. Do this for all scaffold strands until the scaffold has been unified (Fig. 7b). Any surplus strand that remains outside the crosslinked region can be deleted using the "Select" tool and pressing delete.

CRITICAL STEP There should now be only one continuous scaffold strand throughout the network with a single 5 ' and 3 ' terminus.

(vi) Pore design - staple strands (steps vi-viii). Generate the staple strand sequences by selecting the "AutoStaple" function from the toolbar which automatically yields staples across the scaffold with relevant crossovers.

(vii) (Optional) Adjust staple strands to ensure the formation of the desired nanostructure. For example, nicks should not be positioned within 4 bases of a crossover. The staple strands' termini can be modified using the "Select" tool by dragging the square or the triangle to the desired position. CRITICAL STEP To prevent undesired blunt-end stacking interactions between separate DNA nanostructures, omit peripheral staple strands or reduce their length. 
This leaves scaffold single strand loops which limit intermolecular blunt-end stacking interactions between DNA origami structures.

(viii) Scan the strands for a thick line which indicates that the strand is either too long or too short to fit within the program's ideal limit (Fig. 7c). These staples can be cut using the "AutoBreak" function in the toolbar (Fig. d-e). The tool enables idealized staple lengths to be obtained with upper and lower limits. Strands can be manually cut using the "Break" tool.

(ix)Pore design - generating staple strand sequences. To obtain the staple sequences click the "Sequence" button in the toolbar on the right. Once selected, a pop-up menu appears with a choice of common origami scaffolds (standard tab), or the option to generate a custom scaffold (custom tab). The scaffold and staple sequences will now appear in the path panel within each box. The M13mp18 scaffold is recommended given its widespread use, low degree of sequence repetition and commercial availability.

(x) Organizing staples. The staple strands can be colored using the "Paint" function on the right-hand tool bar. This is useful to organize the staples according to domain (e.g. cap or lumen staples) in the spreadsheet. The grouped staples in the 96-well plates can then be used to generate pooled staples for each domain.

(xi) Export the sequences. Use the "Export" function to generate a comma separated variable file (.csv) of the staple sequences. Import the file into Excel (Fig. 7f). The strands can be organized according to their domain via the "Color" column by using the "Sort" function in the "Data" tab.

\section{Predicting nanopore structural dynamics using CanDo's online service and ordering DNA strands. • TIIMIING $1-5$ days}

2. The stability of new DNA nanopore designs can be simulated prior to ordering the component strands. Both nanobarrel and DNA origami-based designs can be simulated using the computer-aided engineering for DNA origami (CanDO) online service. This program uses the .json file from CaDNAno to generate either a coarse or fine-grain simulation of the nanostructure; however, the coarse-grained model requires significantly shorter computation time. Movies can be generated to visualize the thermal fluctuations of the structure. More detailed information on simulation parameters and methods are described on CanDo's website (https://cando-dna-origami.org/) ${ }^{56,62}$.

3. Create an account and log into the CanDo website and navigate to the submission page. Input the information about DNA lattice geometry, mechanical properties, model resolution and other parameters, then upload the .json file from CaDNAno and submit the request. The results of the simulations will be sent via email including the shape, thermal fluctuations and atomic model (optional).

4. Check the simulation results (Fig. 3c, Fig. 3f) to confirm the simulated shape matches the designed structure. In the thermal fluctuation analysis, maximum displacements below $1 \mathrm{~nm}$ are desirable. Predicted fluctuations above $1 \mathrm{~nm}$ should prompt the redesign of the pore. A 
higher rigidity of the structure can, for example, be attained with an increased number of crossovers.

\section{? TROUBLESHOOTING}

5. Order Strands for DNA nanobarrel and DNA origami pores. For DNA nanobarrel pores, procure the oligonucleotides from a commercial supplier. Order on a $100 \mathrm{nmol}$ scale with HPLC purification in single tubes. Suppliers include Integrated DNA Technologies, ATDBio, and Sigma-Aldrich. For DNA origami pores, procure staple strands from a commercial supplier in 96-well plates on a 25-100 nmol scale without HPLC purification using the above suppliers. In addition, order the selected scaffold strand from a commercial supplier, typically supplied at 100-400 nM. Suppliers include Tilibit Nanosystems and New England Biolabs.

\section{Introducing lipid anchors}

6. Introduce hydrophobic lipid anchors onto the DNA nanostructure to facilitate membrane insertion. Two strategies are routinely used, the inclusion of cholesterol modifications at stand termini which anchor the negatively charged DNA nanostructure into lipid bilayers $^{21,22,30,81}$ (Option A), or the introduction of hydrophobic alkyl groups in the DNA backbone phosphorothioate (PPT) modifications to chemically neutralize the PPT's negative charge (Option B). Cholesterol anchors induce a toroidal pore lipid arrangement around the DNA nanopore due to the presence of the surrounding negatively charged backbone (Fig 2c, type II membrane insertion) ${ }^{21,59}$ whilst alkylated PPT's generate a tight seal lipid arrangement to mimic a conventional protein nanopore (Fig 2c, type I membrane insertion) ${ }^{60}$. Cholesterol modifications can be used for both nanobarrel and DNA origami designs, however PPT modifications have only been used for nanobarrel designs to date. In addition, lipid headgroup docking agents can also be employed to generate a membranespanning nanopore, such as avidin and streptavidin ${ }^{29}$.

\section{Option A: Cholesterol lipid anchors • TIMIING $1 \mathrm{~d}$}

(i) Determine the number of cholesterol anchors to be included in the nanopore design. For the $6 \mathrm{HB}$, two to six anchors can be positioned around the pore's perimeter to facilitate membrane insertion (Fig. 3a-c). At least two cholesterol modifications are required to insert the $6 \mathrm{HB}$ into the membrane ${ }^{46,85}$.

- CRITICAL STEP Two to four cholesterol lipid anchors are recommended for a $6 \mathrm{HB}$ design. Higher numbers can result in aggregation issues.

(ii) Positioning of cholesterol anchors in DNA nanobarrel pores. The anchors should be evenly distributed around the DNA barrel. An asymmetric lipid anchor arrangement will lead to membrane-tethering rather than membrane spanning orientations ${ }^{32}$. The cholesterol modifications are generally incorporated at strand termini during solid-phase DNA synthesis. Therefore, the designated position of cholesterol anchors in the $6 \mathrm{HB}$ can be changed by shifting the position of the termini along the duplex.

CRITICAL STEP The cholesterols' position must be within the proposed membranespanning region of the DNA pore.

(iii) Cholesterol anchor number in DNA origami pores. Determine the number of cholesterol anchors to be included in the DNA origami structure. The 72HB contains a large cross-section area which has a higher energetic barrier to achieve membrane insertion ${ }^{21,30,60}$. To overcome 
this more cholesterol anchors should be added, ranging from 19 (ref. ${ }^{28}$ ) to 22 for the $72 \mathrm{HB}$ DNA origami pore ${ }^{30}$. The optimal number for a specific design needs to be determined experimentally, or with computational modeling.

(iv) Cholesterol anchor positioning in DNA origami nanopores (Steps iv-v). DNA origami pores often consist of two distinct sections, a transmembrane stem, and a larger extramembrane cap (Fig. 2, Fig. 3). In these designs, the cholesterol lipid anchors are usually located around the transmembrane stem (Fig. 2a, 72HB pore; Fig. 2d, Central) ${ }^{30}$, or at the base of the cap section to protrude into the bilayer (Fig. 2a, 52HB; Fig. 2d, Top) ${ }^{21}$. Use CaDNAno to identify the target lipid anchor site.

(v) Determine how to incorporate the cholesterol-modified strands into the DNA origami nanopore. The scaffold strand cannot be readily modified; therefore, cholesterol anchors should be introduced into the staple strands. To reduce the high cost of dozens of cholesterol-tagged staple strands, one or two modified strands should be designed to universally bind to all the designated lipid anchor sites. This can be achieved by extending the designated staple strands to bind to the universal cholesterol strands.

$\triangle$ CRITICAL STEP The binding region of cholesterol-modified oligonucleotides must have a melting temperature $\left(\mathrm{T}_{\mathrm{m}}\right)$ above the temperature at which the pore is being used. The $\mathrm{T}_{\mathrm{m}}$ should be at least $5-10{ }^{\circ} \mathrm{C}$ higher.

CRITICAL STEP Use the oligo analyzer tool on the IDT website (https://idtdna.com/calc/analyzer) to determine the $\mathrm{T}_{\mathrm{m}}$. To obtain a higher $\mathrm{T}_{\mathrm{m}}$ value, elongate the DNA sequence, or increase the G-C content.

(vi) Produce the cholesterol-modified oligonucleotides from a commercial supplier. Order on a $100 \mathrm{nmol}$ scale with HPLC purification in single tubes. Suppliers include Integrated DNA Technologies, ATDBio, and Sigma-Aldrich. Cholesterol modifications are usually attached to the oligonucleotide at the 3 ' terminus using a triethylene glycol (TEG) linker. Alternatively, 5' or internal modifications are also available but are more expensive.

CRITICAL STEP For DNA origami pores, cholesterol-modified strands are added in 1.1 molar excess per anchor site and must, therefore, be ordered on a suitable scale.

CRITICAL STEP The DNA sequences used to assemble the $6 \mathrm{HB}$ pores $^{22,487}$ are provided in Supplementary Tables 1 and 2. For the sequences of $72 \mathrm{HB}^{30}$ DNA origami pore, see Supplementary Table 3.

\section{Option B: ipid anchors with alkyl phosophorothioate • TIMIING 1-3 d}

(i) Phosphorothioate modifications. Determine the number and location of phosphorothioate modifications across the nanobarrel-type nanopore. Each strand should not contain more than 25\% PPT sites to avoid aggregation issues during the alkylation procedure ${ }^{47}$.

(ii) Procure phosphorothioate modified oligonucleotides (PPT-DNA) from a commercial supplier. Order on a $100 \mathrm{nmol}$ scale with HPLC purification in single tubes. Suppliers include Integrated DNA Technologies, ATDBio, and Sigma-Aldrich.

CRITICAL STEP The DNA sequences used to assemble nanobarrel $6 \mathrm{HB}^{48}$ are shown in Supplementary Table 2. 
(iii) Dissolve the PPT-DNA oligonucleotides in deionized water to generate a stock solution $(100 \mu \mathrm{M})$.

(iv) Ethylating PPT-DNA (Steps iv-v). Measure out the PPT-DNA (5 nmol, $50 \mu \mathrm{L})$ into a screw-top vial. Remove the water under vacuum using a centrifugal evaporator $(\sim 20$ $\min )$.

(v) Add buffer $1(2 \mu \mathrm{L})$ followed by DMF $(18 \mu \mathrm{L})$ and then iodo-ethane $(5 \mu \mathrm{L})$ to the dry DNA. Secure the lid and heat the solution to $65^{\circ} \mathrm{C}$ for $1.5 \mathrm{~h}$ whilst shaking at $100 \mathrm{x} \mathrm{g}$. ! CAUTION Iodo-ethane is volatile and will evaporate quickly without a tightly sealed vial.

(vi) Desalting ethyl-PPT-DNA (Steps vi-vii). Remove the solvent under vacuum using a centrifugal evaporator for 1-2 $\mathrm{h}$ until dry. Re-dissolve the ethyl-PPT DNA by adding EDTA solution $(100 \mu \mathrm{L}, 0.1 \mathrm{M}, \mathrm{pH} 8.0)$ and heat the mixture to $90^{\circ} \mathrm{C}$ for $5 \mathrm{~min}$ whilst shaking at $100 \mathrm{xg}$.

(vii) Use a NAP-25 column to desalt the ethyl-PPT DNA. Wash three column volumes (15 $\mathrm{mL})$ of deionized water through the column. Load the DNA solution $(100 \mu \mathrm{L})$ onto the column, followed by deionized water $(2 \mathrm{~mL})$, and collect the eluent in fractions $(250$ $\mu \mathrm{L})$.

(viii) Determine the DNA-containing fractions using a UV-Vis spectrophotometer by measuring the absorbance at $260 \mathrm{~nm}$. Combine these fractions and concentrate using a centrifugal evaporator $(\sim 50 \mu \mathrm{L})$.

(ix) Purification of ethyl-PPT DNA. Use a 4-20\% PAGE gel to purify the ethyl-PPT DNA in buffer 2. Add gel loading dye $(10 \mu \mathrm{L})$ to the DNA solution $(50 \mu \mathrm{L})$ and load the mixture into the well. Run the gel at $140 \mathrm{~V}$ for $30 \mathrm{~min}$ at RT. For details on how to run a gel, see step 8(B) i-v. Stain and image the gel bands (step 8(B) iv-x for details).

(x) Cut out the product bands with a clean scalpel and place in a plastic vial (1.5 mL). Crush the gel fragment with a pipette tip into a fine slurry.

(xi) Add deionized water $(150 \mu \mathrm{L})$ and shake at $50{ }^{\circ} \mathrm{C}$ for $30 \mathrm{~min}$ at $100 \mathrm{x}$ g. Place the plastic vial in a centrifuge and spin at $15,700 \mathrm{x} g$ for $5 \mathrm{~min}$. Collect the supernatant $(\sim$ $100 \mu \mathrm{L})$.

(xii) Remove residual SDS by purifying the collected sample using a NAP-25 column (see steps vi-vii). Concentrate as required (see step viii).

(xiii) The ethyl-PPT DNA should be analyzed by mass spectrometry to confirm successful alkylation. In addition, the sample should be compared to the non-modified strand using SDS PAGE in step 8(B).

\section{Nanopore assembly}


7. The assembly protocol will vary for different DNA nanopores designs. For the assembly for nanobarrel-type pores follow Option A, for larger DNA origami pores follow Option B.

\section{Option A: Assembly of nanobarrel pores • TIIMIING $3 \mathrm{~h}$}

(i) Determine the folding buffer. The nanobarrel-type 6HB pore 22 can be folded efficiently in a range of different buffers and salts to suit specific applications ${ }^{45}$. Suggested folding buffers include: buffer 3 (supplemented with 1-20 $\mathrm{mM} \mathrm{MgCl}_{2}$ ), buffer 4, and buffer 5 . The pore can be annealed using a thermal cycler at a concentration of $1 \mu \mathrm{M}$ in $100 \mu \mathrm{L}$. Higher concentrations are possible but may require experimental validation. Make a 10x stock of your desired folding buffer.

CRITICAL STEP Cholesterol modifications can cause the pores to aggregate under some folding conditions. To alleviate aggregation, surfactants including n-octyl-oligooxyethylene (OPOE) can be added to the folding mixture $(1.5 \%(\mathrm{v} / \mathrm{v}))^{22,45}$.

(ii) Preparing oligonucleotides for folding. Dissolve the stock oligonucleotides in deionized water to generate a stock solution $(100 \mu \mathrm{M})$ and vortex until dissolved $(\sim 30$ s). Hydrophobic strands may require heating to $50^{\circ} \mathrm{C}$ for $5 \mathrm{~min}$ to completely dissolve.

(iii) Folding Protocol. Add stoichiometric amounts of each component oligonucleotide (1 $\mu \mathrm{L})$ to a vial $(100 \mu \mathrm{L})$ containing the water and buffer reagents. Exemplary amounts for the $6 \mathrm{HB}^{22}$ are shown in the table below:

\begin{tabular}{|l|l|l|}
\hline Component & Amount & Final concentration \\
\hline 6HB oligonucleotides & $1 \mu \mathrm{L}$ & $1 \mu \mathrm{M}($ each $)$ \\
\hline Folding buffer $(10 \mathrm{x})$ & $10 \mu \mathrm{L}$ & $1 \mathrm{x}$ \\
\hline Water & $84 \mu \mathrm{L}$ & - \\
\hline Total & $100 \mu \mathrm{L}$ & - \\
\hline
\end{tabular}

(iv) Place the vial into the thermal cycler. Heat to $95^{\circ} \mathrm{C}$ and cool to $4{ }^{\circ} \mathrm{C}$ at a rate of $0.5^{\circ} \mathrm{C}$ per min. Faster cooling rates are also possible with the $6 \mathrm{HB}$ nanopore.

? TROUBLESHOOTING

PAUSE POINT Nanobarrel pores are stable for up to two weeks when stored at $4{ }^{\circ} \mathrm{C}$; however lipid anchors may cause them to aggregate within this timeframe. Pores can be stored frozen for up to 1 month.

Option B: Assembly of DNA origami pores - TIMIING 1-8 d, depending on the complexity of the structures.

(i) Mixing the origami strands. Identify the target staple strands in the stock 96-well plates. For the $72 \mathrm{HB}$ pore $^{30}$ (Fig 3b), there are 240 core staple strands. These are typically supplied at $100 \mu \mathrm{M}$. The staple strands can be mixed together using a multi-channel pipette by combining equal volumes on a sheet of freshly cleaved Parafilm. Once the staple master mix is generated, a final staple concentration of $416 \mathrm{nM}$ will be obtained. 
(ii) Incorporating the cholesterol lipid anchors. Add the cholesterol lipid anchor strands to the staple mixture. Typically, the universal cholesterol strands are added at 1.1 eq. per binding site.

The cholesterol lipid anchor strands can alternatively be added to DNA origami nanopores after folding and purification. To incorporate the cholesterol oligonucleotides after purification (Step 5), incubate the strands at $30{ }^{\circ} \mathrm{C}$ for $30 \mathrm{~min}^{30}$.

? TROUBLESHOOTING

(iii) Mix the scaffold strand and staples at a molar ratio of 1:5, respectively. The origami solution is normally made-up in buffer 3 (supplemented with $14 \mathrm{mM} \mathrm{MgCl}_{2}$ ) using the following recipe:

\begin{tabular}{|l|l|l|}
\hline Component & Amount & Final concentration \\
\hline M13mp18 & $125 \mu \mathrm{L}$ & $50 \mathrm{nM}$ \\
\hline Staples master mix & $601 \mu \mathrm{L}$ & $200 \mathrm{nM}($ each $)$ \\
\hline Folding buffer $(10 \mathrm{x})$ & $100 \mu \mathrm{L}$ & $1 \mathrm{x}$ \\
\hline Water & $174 \mu \mathrm{L}$ & - \\
\hline Total & $1000 \mu \mathrm{L}$ & - \\
\hline
\end{tabular}

(iv) Folding protocol. The folding of DNA origami nanopores is more complex than nanobarrel versions. Multi-layer origami structures have a higher number of interduplex crossovers which require slower annealing rates to form efficiently. Annealing protocols can vary from one day to over a week ${ }^{30}$. Assemble the 72HB DNA origami nanopore (Fig. 3d-f) using an 8 day-long protocol involving two phases: first from 80 to $60{ }^{\circ} \mathrm{C}$ at a rate of $1{ }^{\circ} \mathrm{C}$ per $5 \mathrm{~min}$, followed by 60 to $20^{\circ} \mathrm{C}$ at a rate of $1{ }^{\circ} \mathrm{C}$ per 300 $\min ^{30}$.

? TROUBLESHOOTING

PAUSE POINT DNA origami pore can be stored for up to 2 weeks at $4{ }^{\circ} \mathrm{C}$. Purified structures are more prone to aggregation so it is better to store pores in an unpurified state for longer periods. Pores can be frozen and stored at $-20^{\circ} \mathrm{C}$ for 1 month.

\section{Gel electrophoretic characterization}

8. Two types of gel electrophoresis can be used to characterize DNA nanopores, agarose gel electrophoresis (Option A) and polyacrylamide gel electrophoresis (PAGE) (Option B). Agarose gel electrophoresis is suitable for both nanobarrel and DNA origami pores, whilst PAGE is suitable for nanobarrels only.

\section{Option A: Agarose gel electrophoresis • TIIMING 2-3 h}

CRITICAL The following procedure is tailored for DNA nanobarrel-type pores. The modifications required for larger DNA origami structures are indicated in the Critical Steps.

(i) Casting an agarose gel (steps $i$-vi). Assemble the agarose gel tray on a level surface.

(ii) To make a $2 \%(\mathrm{w} / \mathrm{v})$ agarose gel, add the agarose powder $(3 \mathrm{~g})$ to a conical flask $(250 \mathrm{~mL})$ followed by buffer $3(150 \mathrm{~mL})$. Weigh the conical flask and record the weight.

CRITICAL STEP For larger DNA origami structures, conduct the protocol with a $1.5 \%$ (wt/vol) agarose gel and, optionally, supplement buffer 3 with 1-20 $\mathrm{mM} \mathrm{MgCl}$. 
(iii) Heat the mixture in a microwave on a medium setting until it starts to boil. Allow the slurry to cool for 5 mins then gently swirl the mixture. Repeat until the agarose is fully dissolved. Reweigh the conical flask and replenish any evaporated water with deionized water $(\sim 10 \mathrm{~mL})$. ! CAUTION The boiling solution is prone to bumping. Wear thermal gloves, laboratory coat and safety glasses.

CRITICAL STEP The agarose must be completely dissolved in the buffer. Visually confirm that no agarose beads remain.

(iv) Add ethidium bromide $(5 \mu \mathrm{L})$ to the molten agarose and mix thoroughly.

! CAUTION Ethidium bromide is a suspected carcinogenic. Only handle the solution in a fume hood wearing gloves, a lab coat and eye protection. Waste contaminated with ethidium bromide must be disposed of separately according to local regulations.

(v) Carefully pour the molten agarose into the gel tray. Brush any bubbles to one side using a pipette tip, then assemble the comb in the holder. Let the gel set for $\sim 30$ min until solidified.

(vi) Carefully remove the comb and place the gel with gel holder into the tank. Pour in buffer $3(\sim 650 \mathrm{~mL})$ and ensure the gel is fully submerged. Place the tank in a fridge (or ice bath) and thermally equilibrate the running buffer between $4-8{ }^{\circ} \mathrm{C}$.

! CAUTION Do not remove the comb before the gel has set as this will damage the wells. The gel should be slightly translucent when set.

CRITICAL STEP Use a thermometer to confirm the temperature of the running buffer is between $4-8{ }^{\circ} \mathrm{C}$.

(vii) Gel loading (steps vii-viii). Mix the samples in plastic vials using the following recipe:

\begin{tabular}{|l|l|l|}
\hline & Nanobarrel pores & DNA origami pores \\
\hline Amount of pore & $2 \mu \mathrm{L}, 1 \mu \mathrm{M}$ & $10 \mu \mathrm{L}, 10 \mathrm{nM}$ \\
\hline Folding buffer $(1 \mathrm{x})$ & $13 \mu \mathrm{L}$ & $5 \mu \mathrm{L}$ \\
\hline Gel loading dye & $5 \mu \mathrm{L}$ & $5 \mu \mathrm{L}$ \\
\hline
\end{tabular}

? TROUBLESHOOTING

(viii) Load an appropriately sized DNA ladder $(5 \mu \mathrm{L})$ into the first well of the gel, followed by the sample-dye mixtures $(10 \mu \mathrm{L})$. Additional control constructs can be included to aid analysis, such as, assembled barrels with and without hydrophobic lipid anchors, or partially assembled barrels.

(ix) Running the gel. Assemble the lid and run the gel at $60 \mathrm{~V}$ for $60 \mathrm{~min}$ between $4-8{ }^{\circ} \mathrm{C}$.

CRITICAL STEP The gel must be completely submerged in running buffer, and the lid and tank correctly aligned. The low temperature is required to prevent denaturation of the assembled structures.

CRITICAL STEP For larger DNA origami structures, run the gel at $60 \mathrm{~V}$ for $90 \mathrm{~min}$ at 4-8 ${ }^{\circ} \mathrm{C}$. The addition of $\mathrm{MgCl}_{2}(1-20 \mathrm{mM})$ in the running buffer may be necessary to maintain the structural integrity of large DNA origami pores. However, $\mathrm{MgCl}_{2}$ may cause the running buffer and gel to heat up and potentially damage the structure. The exact conditions must be experimentally determined.

(x) Imaging the gel. Remove the gel and visualize the bands using a gel documentation system capable of detecting the DNA bands stained with ethidium bromide. Adjust the exposure, 
brightness and contrast until the bands of interest are clear, then save the image. An example gel image for the 6HB nanobarrel is shown in Fig. 8a. An example of the DNA origami 72HB nanopore is shown in Fig. 8c.

! CAUTION UV light is harmful to eyes and skin. Always use a protective UV face shield.

? TROUBLESHOOTING

\section{Option B: PAGE・TIMIING 2-3 h}

(i) Remove the pre-cast PAGE gel from its packaging following the manufacturer's instructions. Place the gel into the cassette and fill the chamber and tank with buffer 6 . Use a pipette to wash the wells and remove any bubbles. Assemble the lid and place the gel box in the fridge (or ice bath).

CRITICAL STEP The gel and buffer dam must be assembled correctly in the cassette to prevent leakage. Use a thermometer to ensure the running buffer temperature is between 4$8{ }^{\circ} \mathrm{C}$.

CRITICAL STEP Sodium dodecyl sulfate (SDS) $(0.1 \%(\mathrm{v} / \mathrm{v}))$ can be used in the running buffer (buffer 2) to help resolve streaky bands arising from lipid anchor-modified DNA nanostructures.

(ii) Pre-equilibrate the gel at $120 \mathrm{~V}$ for $30 \mathrm{~min}$ between $4-8{ }^{\circ} \mathrm{C}$.

(iii) Loading the samples. Mix the samples in plastic vials using the following recipe:

\begin{tabular}{|l|l|}
\hline Amount of pore & $2 \mu \mathrm{L}, 1 \mu \mathrm{M}$ \\
\hline Folding buffer $(1 \mathrm{x})$ & $13 \mu \mathrm{L}$ \\
\hline Gel loading dye & $5 \mu \mathrm{L}$ \\
\hline
\end{tabular}

? TROUBLESHOOTING

(iv) Load a $100 \mathrm{bp}$ DNA ladder $(5 \mu \mathrm{L})$ into the first lane, followed by the sample-dye mixture $(8 \mu \mathrm{L})$ in a separate lane.

(v) Running the gel. Assemble the lid, run the gel for 60 min at $115 \mathrm{~V}$.

CRITICAL STEP The gel must be completely submerged in buffer and the lid and gel tank must be correctly aligned. The low temperature prevents possible denaturation of assembled structures.

CRITICAL STEP The PAGE conditions may need to be adjusted depending on the pore's dimensions, hydrophobicity and structural stability.

(vi) Remove the gel from its holder

(vii) (Optional) When SDS has been added to the running buffer in Step (i), carefully remove the gel from its container using the extractor tool and submerge it in a staining tank filled with deionized water $(50 \mathrm{~mL})$. Remove the residual SDS from the gel by shaking gently for $10 \mathrm{~min}$. Discard the water

(viii) Staining (steps viii-ix). Carefully remove the gel from its container using the extractor tool. Place the gel into ethidium bromide staining solution $(50 \mathrm{~mL}, 0.1 \%(\mathrm{v} / \mathrm{v}))$ and shake gently for $5 \mathrm{~min}$. Then decant the solution. 
CRITICAL STEP Handle PAGE gels carefully as they are prone to tearing.

! CAUTION Ethidium bromide is a suspected carcinogenic. Only handle it in a fume hood wearing gloves, a lab coat and eye protection. Waste contaminated with ethidium bromide must be disposed of separately according to local regulations.

(ix) Remove unbound ethidium bromide by washing the gel with deionized water $(50 \mathrm{~mL})$ for $10 \mathrm{~min}$.

(x) Visualize the bands using a gel documentation system capable of detecting the DNA bands stained with ethidium bromide. Adjust the exposure, brightness and contrast until the bands of interest are clear, then save the image. An example gel image for the 6HB nanobarrel is shown in Fig. 8b.

! CAUTION UV light is harmful to eyes and skin. Always use a protective UV face shield.

? TROUBLESHOOTING

\section{Purification}

9. DNA origami structures need to be purified from excess staples strands prior to use. Three methods routinely used are outline in Table 3. For gel extraction follow Option A, for polyethylene glycol (PEG) precipitation follow Option B, and for size exclusion chromatography (SEC) follow Option C. No purification is typically required for simpler DNA nanobarrel structures which generally fold in quantitative yield.

Table 3 Comparison of purification methods presented in this protocol.

\begin{tabular}{|l|l|l|}
\hline Method & Advantages & Disadvantages \\
\hline A. Gel extraction & $\begin{array}{l}\text { Inexpensive } \\
\text { Dimer separation }\end{array}$ & $\begin{array}{l}\text { Low recovery yields } \\
\text { Possible agarose contamination } \\
\text { Requires staining to visualize } \\
\text { the bands } \\
\text { Extensive hands-on time }\end{array}$ \\
\hline $\begin{array}{l}\text { B. Polyethylene glycol } \\
\text { (PEG) precipitation }\end{array}$ & $\begin{array}{l}\text { Good recovery yield } \\
\text { Low contamination }\end{array}$ & $\begin{array}{l}\text { Insufficient separation of dimers } \\
\text { and higher order structures } \\
\text { Possible sample aggregation }\end{array}$ \\
\hline $\begin{array}{l}\text { C. Size exclusion } \\
\text { chromatography (SEC) }\end{array}$ & $\begin{array}{l}\text { Automated purification } \\
\text { Readily quantifiable }\end{array}$ & $\begin{array}{l}\text { Insufficient separation of dimers } \\
\text { and higher order structures }\end{array}$ \\
\hline
\end{tabular}

\section{Option A: Gel extraction • TIIMING 1-2 d}

(i) Prepare a $1 \%(\mathrm{w} / \mathrm{v})$ agarose gel using buffer 3 (supplemented with $10 \mathrm{mM} \mathrm{MgCl}$ ) with wide combs (lane width of $2.7 \mathrm{~cm}$ ) following step $8(\mathrm{~A}) \mathrm{i}-\mathrm{x}$.

(ii) Add the folded DNA origami structure $(100 \mu \mathrm{L}, 20 \mathrm{nM})$ to SDS-free gel loading dye (30 $\mu \mathrm{L})$ in a plastic tube $(1.5 \mathrm{~mL})$, then load all the contents into the well of the agarose gel.

(iii) Running the gel. Assemble the lid and run the gel at $65 \mathrm{~V}$ for $90 \mathrm{~min}$ at $4-8{ }^{\circ} \mathrm{C}$. 
CRITICAL STEP Ensure the gel is submerged in running buffer and the lid and gel tank correctly aligned. The temperature of the gel is critical to prevent possible denaturation of assembled structures. $\mathrm{MgCl}_{2}$ in the running buffer may cause the system to heat up.

(iv) To image the DNA gel bands, follow step 8(A) $\mathrm{x}$.

(v) Extracting DNA from the gel (Steps v-viii). Using a disposable scalpel, carefully cut out the band of interest and remove excess liquid with precision wipes.

CRITICAL STEP Cut the band as close as possible and limit the UV exposure to prevent UVinduced photodamage.

(vi) Transfer the sample into a plastic vial $(1.5 \mathrm{~mL})$ using a pipette and store the sample in the freezer $\left(-20^{\circ} \mathrm{C}\right)$ for $14 \mathrm{~h}$.

(vii) Wrap two microscope slides $(75 \times 25 \mathrm{~mm})$ in freshly cleaved Parafilm. Add the frozen agarose slab onto one Parafilm-covered-slide. Cut the gel into small pieces using the scalpel, then place the second Parafilm-slide on top of the cut agarose.

(viii) Carefully squeeze the gel between the two slides. Collect the expelled liquid using a pipette and transfer to a plastic vial.

CRITICAL STEP Squeeze the sample several times to maximize the recovery yield.

PAUSE POINT

Collect the samples in labelled tubes, and store in a $-20{ }^{\circ} \mathrm{C}$ freezer until further use.

\section{Option B: PEG precipitation -TIIMING 1-2 d}

(i) Add the assembled DNA origami pore $(50 \mu \mathrm{L}, 50 \mathrm{nM})$ and buffer $8(50 \mu \mathrm{L})$ into a plastic vial $(1.5 \mathrm{~mL})$.

(ii) Vortex the sample for $3 \mathrm{~s}$, then centrifuge at $8,000 \mathrm{x}$ g for $30 \mathrm{~min}$ at $25^{\circ} \mathrm{C}$.

CRITICAL STEP The plastic tube should be placed in the centrifuge, so the lid faces the center of the rotor. Use a marker pen to identify the location of the pellet in the plastic tube after centrifugation. The pellet will be transparent, and the marked position will help identify the location of the DNA.

(iii) Carefully remove the tube from the centrifuge and extract the supernatant $(\sim 45 \mu \mathrm{L})$ using a pipette.

CRITICAL STEP Take care not to disrupt the pellet at the bottom of the vial. Place the pipette tip opposite the position marked on the side of the plastic tube.

(iv) Add buffer $8(100 \mu \mathrm{L})$ to the tube and spin the sample for another $30 \mathrm{~min}$ at $8,000 \mathrm{xg}$ at $25^{\circ} \mathrm{C}$. 
(v) Remove supernatant $(\sim 90 \mu \mathrm{L})$ using a pipette taking care to not disrupt the pellet.

(vi) Add buffer $8(100 \mu \mathrm{L})$ and repeat steps (iii) - (v) two more times.

(vii) To resuspend the DNA origami pore, add buffer $7(50 \mu \mathrm{L})$ and vortex for 3 min, then gently shake for $20 \mathrm{~h}$ at $30^{\circ} \mathrm{C}$ using a thermomixer.

\section{PAUSE POINT}

Collect the samples in labelled tubes, and store in a $-20^{\circ} \mathrm{C}$ freezer until further use.

\section{Option C: Size Exclusion Chromatography (SEC) • TIMING 6 h}

(i) Equilibrating the system. The SEC system and column are stored in ethanol $(20 \%(\mathrm{v} / \mathrm{v}))$ and must be transferred into water. Place the system inlet lines into freshly filtered and degassed water (1 L). Under the "Manual" settings tab, select "Pump", and "Pump Wash Purifier". Then select "A1" and "B1" and select "Execute".

(ii) Under the pump instruction, select "System Wash" (10 mL) and press "Execute".

(iii) Washing the loop. Under the "Flow Path" options, select "Injection Valve" and "Load". Then, draw deionized water $(10 \mathrm{~mL})$ into a disposable syringe and wash the loop.

(iv) Washing the column. In the "Flow Rate" tab enter a value of " $0.5 \mathrm{~mL}$ per min", then set the "Column Position" (depends on system) and "End Timer" to "60 mL" (two column volumes) and select "Execute".

CRITICAL STEP The column pressure should not exceed 1.8 MPa (specific to each column - see manufacturer's instructions).

(v) Once the run is complete, repeat steps (i) - (iv) using buffer 3 (supplemented with 14 $\mathrm{mM} \mathrm{MgCl}_{2}$ ).

(vi) Loading DNA onto the column (steps vi-viii). In the "Flow Rate" tab enter a value of "0.5 mL per min", set the "Column Position" (depends on system), and set the "Injection Valve" to "Load", in the "Monitor" tab set the "wavelength" to "260, 280 and $345 \mathrm{~nm}$ ", and the "End Timer" to "60 mL", then select "Execute". 
(vii) Remove the buffer-containing syringe from the injection valve and place the sample-containing syringe $(1 \mathrm{~mL})$ into the injection valve and load the sample into the loading loop.

(viii) Select "Inject", to transfer the sample onto the column. Once the sample has completely run into the column, set the "Injection Valve" back to "Load" and press "Execute"

CRITICAL STEP This will ensure no air bubbles are introduced as these will damage the column.

(ix) Place a 96-well plate onto the cassette tray. Then, using the "Manual" tool, select the parameters found under the "Fractionation" tab and add the "96-well plate", set the "Fraction Size" to "0.25 mL", then select "Execute".

CRITICAL STEP The handle of the cassette tray must be pulled upwards. Check the 96-well plate and the chromatogram regularly to confirm that fractions are collected in the correct well.

(x) Once the run is complete, identify the DNA origami fractions and combine in a plastic vial $(1.5 \mathrm{~mL})$.

(xi) Transfer the system to deionized water and repeat steps (iii) - (v) to wash the loop and column. Finally, transfer the system back to ethanol $(20 \%(\mathrm{v} / \mathrm{v}))$, repeat steps (iii) - (v) to wash the loop and column.

\section{PAUSE POINT}

Collect the samples in labelled tubes, and store in a $-20{ }^{\circ} \mathrm{C}$ freezer until further use.

Determining nanopore concentration after purification • TIMIING $10 \mathrm{~min}$

10. Using a Nanodrop 800 select the standard methods tool "Single Sample" and then "Nucleic Acid", set the sample type to "DNA-50" for double stranded DNA $\left(\mathrm{OD}_{260 \mathrm{~nm}} 1=\right.$ $50 \mu \mathrm{g}$ per $\mathrm{mL}$ ).

11. Clean the pedestal by pipetting water $(2 \mu \mathrm{L})$, then wipe dry with a precision wipe.

12. Apply buffer 3 (supplemented with $14 \mathrm{mM} \mathrm{MgCl}_{2}, 2 \mu \mathrm{L}$ ) to the pedestal. Close the sampling arm and select "Blank". 
13. Clean the pedestal with wipes, then add the DNA sample $(2 \mu \mathrm{L})$. Close the sampling arm and select "Measure". Record the absorbance and DNA concentration in $\mu \mathrm{g}$ per $\mathrm{mL}$.

14. Once the measurement is complete, open the sampling arm and wipe the samples from both the upper and lower pedestals.

15. Repeat steps (iv) - (v) two more times. Average the absorbance and concentration values.

16. Calculate the molecular weight of the DNA origami structure ( 660 Da per base pair). Use this to convert the $\mu \mathrm{g}$ per $\mathrm{mL}$ reading to $\mathrm{nM}$.

\section{Sample preparation and imaging with transmission electron microscopy (TEM) -TIIMING $\sim 1 \mathrm{~d}$}

17. Glow-discharge TEM grids (Steps 17-21). Wrap a glass slide with a piece of freshly cleaved Parafilm and place TEM grids upright on the surface.

18. Load the slide into the chamber of the glow discharger. Assemble the lid and ensure a tight seal is formed, then check the knobs for "Leak" and "Vent" are closed.

19. Turn on the vacuum pump, wait until the pressure in the chamber has dropped to $\sim 0.2$ $\mathrm{Pa}$, and then slowly open the "Leak" knob until the air pressure is between 0.6-0.8 Pa.

20. Press the "Test" button to confirm the glow discharger is working by the appearance of a bright purple glow. Set the processing time to $45 \mathrm{~s}$ and start the glow-discharging process.

CRITICAL STEP If a different color is observed this means the desired pressure has not been reached.

21. After the process is complete, slowly open the "Vent" knob to restore air pressure in the chamber, take out the glass slide, and place the grids in a clean box.

22. TEM is a sensitive imaging technique capable of visualizing DNA nanopores prepared using either the nanobarrel or DNA origami methods. In order to prepare samples for all pore types follow Option A. In order to visualize DNA origami pores inserted into small unilamellar vesicles using TEM follow Option B.

\section{Option A: Preparation of TEM samples without membranes • TIIMING $\sim 1 \mathrm{~h}$}

(i) Centrifuge the $2 \%(\mathrm{w} / \mathrm{w})$ uranyl formate solution at $15,700 \mathrm{x}$ g for $5 \mathrm{~min}$. Add two droplets of this staining solution ( $6 \mu \mathrm{L}$ each, $5 \mathrm{~cm}$ apart) on a piece of freshly cleaved Parafilm.

(ii) Deposit the sample $(6 \mu \mathrm{L}, 1-10 \mathrm{nM})$ onto the glow discharged TEM grid for $10 \mathrm{~s}$.

CRITICAL STEP If the sample adheres poorly to the grid extend the incubation time to $30 \mathrm{~s}$.

(iii) Carefully and swiftly remove the liquid by blotting with the side of filter paper. 
(iv) Place the grid face down on the first droplet of staining solution. Then, immediately remove the grid and blot the solution onto filter paper. Then submerge the grid for $10 \mathrm{~s}$ into a second droplet of staining solution, then blot the excess liquid with filter paper.

CRITICAL STEP The duration of the staining time will directly affect the contrast on the microscope. If the duration is too short then the DNA nanostructures will not be visible, whilst too long will produce dark black clusters.

(v) Allow the grid to air-dry for at least 30 min before imaging.

PAUSE POINT Samples can now be stored for up to 2 years at RT, but they must be kept dry.

\section{Option B: Preparation of TEM samples for cholesterol-modified DNA origami pores inserted into SUVs. • TIIMING $\sim 3 \mathrm{~h}$}

i. Preparation of small unilamellar vesicles (SUVS) (Steps $i$-vi). Add 1,2-dioleoyl-sn-glycero3-phosphocholine (DOPC, $70 \mu \mathrm{L}, 10 \mathrm{mM}$, in chloroform) and 1,2-dioleoyl-sn-glycero-3phosphoethanolamine (DOPE, $30 \mu \mathrm{L}, 10 \mathrm{mM}$, in chloroform) to a round bottom flask ( 5 $\mathrm{mL}$ ) to generate a 7:3 molar ratio of each lipid, respectively. Remove the chloroform using a rotary evaporator for $20 \mathrm{~min}$ at $40{ }^{\circ} \mathrm{C}$ to form a thin lipid film.

ii. Attach the flask to a high vacuum line and dry the lipid film for $1 \mathrm{~h}$.

iii. Add buffer $7(1 \mathrm{~mL})$ to the flask and vortex for $3 \times 10 \mathrm{~s}$. Then place the flask in a bathsonicator for $20 \mathrm{~min}$ at $30{ }^{\circ} \mathrm{C}$ to form lipid vesicles

! CAUTION Sonication uses high energy sound waves. Use a float or clamp system to support the round bottom flask. Never immerse your fingers in the water bath when sonication is on.

iv. Assemble the extruder with a $100 \mathrm{~nm}$ track-etched polycarbonate membrane according to the manufacturer's instructions.

CRITICAL STEP Take care not to over-tighten the extruder as this can cause the polycarbonate membrane to tear leading to membrane leakage and ineffective sizing.

v. Wash the extruder by passing buffer $7(500 \mu \mathrm{L})$ through the system several times, then discard the solution.

vi. Load the SUV suspension (1 mL) into one syringe, and carefully insert into the extruder system. Pass the lipid suspension 25 times between the syringes. Afterwards, transfer the SUV suspension $(\sim 1 \mathrm{~mL})$ to a plastic vial $(1.5 \mathrm{~mL})$.

PAUSE POINT Store at $4{ }^{\circ} \mathrm{C}$ for up to $48 \mathrm{~h}$. Vortex for $2 \mathrm{~s}$ prior to use.

CRITICAL STEP An odd number of passes is critical to obtain size-selected vesicles. An even number of passes may result in unextruded vesicles, lipid debris and other contaminants being present in the extruded suspension.

vii. Preparation of origami samples incubated with vesicles (Steps vii-viii). Dilute the SUV solution $(6 \mu \mathrm{L})$ into buffer $7(94 \mu \mathrm{L})$ in a plastic vial $(100 \mu \mathrm{L})$, then vortex for $3 \times 10 \mathrm{~s}$.

viii. Mix the SUV solution $(20 \mu \mathrm{L})$ and DNA origami $(20 \mu \mathrm{L}, 10 \mathrm{nM})$ into buffer $7(160 \mu \mathrm{L})$. Vortex for $3 \mathrm{x} 10 \mathrm{~s}$ then leave to incubate at RT for $30 \mathrm{~min}$. 
ix. Preparation of TEM samples with vesicles (Steps $i x-x i)$. Centrifuge the $2 \%(\mathrm{w} / \mathrm{w})$ uranyl formate solution at $15,700 \mathrm{x}$ g for $5 \mathrm{~min}$. On a piece of freshly cleaved Parafilm, add two droplets ( $6 \mu \mathrm{L}$ each, $5 \mathrm{~cm}$ apart) of fresh uranyl formate staining solution for each sample.

x. For staining, repeat step 22(A)ii-iv.

xi. Allow the grid to air-dry for at least 30 min before imaging.

PAUSE POINT Samples can now be stored for up to 2 years at RT, but they must be kept dry.

23. TEM imaging and analysis (Steps 23-26). Insert the stained TEM grids into a beamaligned TEM, wait for the indicators of the vacuum to turn green, rotate and load the sample inside.

24. Turn on the filament and wait for the instrument to reach the set power.

25. Setup the appropriate parameters of magnification, aperture, and exposure, and survey the sample grid with the navigation controller.

CRITICAL STEP The steps for TEM imaging vary between samples and instruments. For the images shown in Fig. 9c-d, the settings included a 20,000x magnification, second aperture position and a $0.2 \mathrm{~s}$-long exposure time.

26. Find a field of view with the targeted DNA nanostructures, check if the shape and dimensions are as expected, and save the image in a . $d m 3$ format. Analyze the raw dataimages using Gatan software to measure the size and angle information of the nanostructures. To obtain images readable for other image editing or analysis software like Image J, the raw data needs to be converted to .tiff format.

? TROUBLESHOOTING

Sample preparation and imaging with atomic force microscopy (AFM) $\bullet$ TIMING $\sim 1 \mathrm{~d}$

27. To prepare a new mica disk, deposit a droplet of glue $(\sim 10 \mu \mathrm{L})$ in the center of the metal disc, then place a single mica disk on top of the glue and compress. Allow the glue to dry for $20 \mathrm{~min}$ before use.

28. Cleave a fresh layer of mica by placing newly dispensed tape on top, then peel away the tape without touching the freshly cleaved mica surface.

CRITICAL STEP Confirm successful cleavage of the old layer by visually identifying the presence of the old mica layer on the tape.

29. To prepare samples of DNA nanopores on mica in the absence of membranes follow Option A. For DNA nanopores in supported lipid bilayers follow Option B.

\section{Option A: Adhering DNA nanostructures on mica $\cdot$ TIIMING $\sim 10 \mathrm{~min}$}

i. Deposit the DNA nanostructures (1-100 nM, 2-10 $\mu \mathrm{L}$, in buffer 3 (supplemented with 14 $\mathrm{mM} \mathrm{MgCl}_{2}$ )) on the mica and allow to adhere for $5 \mathrm{~min}$. Then add buffer 3 (supplemented with $14 \mathrm{mM} \mathrm{MgCl} 2,50 \mu \mathrm{L}$ ). 
CRITICAL STEP For highly symmetrical DNA nanostructures which can have higher lateral mobility on the mica surface, poly-lysine solution $(5 \mu \mathrm{L})(0.1 \%(\mathrm{v} / \mathrm{v})$ can be added to the freshly cleaved layer first, then washed with buffer 3 (supplemented with $14 \mathrm{mM} \mathrm{MgCl}_{2}, 5$ x $\left.100 \mu \mathrm{L}\right)$.

\section{Option B: Adhering DNA nanostructures to mica-supported lipid bilayers • TIMIING}

$2 \mathrm{~h}$

i. Follow step 22(B) i-vi to produce SUVs in buffer 4.

ii. Add buffer $9(50 \mu \mathrm{L})$ to freshly cleaved mica, followed by the vesicle suspension $(1 \mu \mathrm{L})$ and leave for $5 \mathrm{~min}$.

CRITICAL STEP The $\mathrm{Ca}^{2+}$ ions cause the vesicles to rupture and cover the mica surface in a lipid bilayer.

iii. Wash excess SUVs by adding and discarding buffer $4(5$ x $50 \mu \mathrm{L})$.

iv. Add the DNA nanopore ( $1 \mu \mathrm{L}, 1-100 \mathrm{nM}$ in buffer 4$)$ to the solution and wait for $5 \mathrm{~min}$ for the pores to insert into the bilayer.

30. AFM imaging (Steps 30-37). Switch the instrument on, open the Nanoscope software and select "Tapping Mode". Place the disc on the magnetic scanner and ensure the stage is low enough to prevent contact with the cantilevers.

CRITICAL STEP If the stage is too high the cantilevers will come into contact with the surface and damage the tips.

31. Assemble the holder, connect the laser cable and switch on the camera system.

32. Using plastic tweezers, carefully pick up the cantilevers and mount it in the fluid cell holder.

33. Align the laser on "Tip E" of the cantilever, then find a flat area to image.

CRITICAL STEP Use the camera to inspect the mica surface to check for defects. Defects appear as thin black lines.

CRITICAL STEP If air bubbles form around the tip, remove the bubbles by remounting the holder.

34. Lower the fluid cell holder until "Tip B" touches the mica surface. Then select "Engage" using appropriate voltage engage set points, typically $10-40 \mathrm{mV}$, scanning at $4 \mathrm{~Hz}$, and monitor the force curve to confirm successful contact.

35 . Increase the scan area to $2 \mu \mathrm{m}$ and scan at 256 points per line. Optimize the feedback gain (typically 20 for DNA nanostructures) and z-height limit $(1.5 \mu \mathrm{m})$ to ensure successful imaging. 
CRITICAL STEP Too much gain will generate measurement noise. Monitor the zlimit and ensure it does not increase, if required retract from the surface and re-engage to increase the tip's lifespan.

36. To generate high-resolution images, increase the samples per line to 512 points on the desired scan size.

37. To finish the scan, reduce the scan size to "0 $\mathrm{nm}$ " and apply the "Withdraw Function".

38. Data processing (Steps 38-40). Open the Gwyddion software and import selected .spm files.

39. Flatten the image using the "Line-by-Line function", and remove any tilts using a first-order polynomial.

40. Adjust the color scale to show preferred regions of interest. Perform line-sectional analysis and export results as required.

\section{? TROUBLESHOOTING}

\section{Gel assay to determine pore-membrane binding • TIIMING $4 \mathrm{~h}$}

41. SUV preparation and characterization (Steps 41-42). Prepare SUVs using 1-palmitoyl-2oleoyl-glycero-3-phosphocholine (POPC, $100 \mu \mathrm{L}, 10 \mathrm{mM}$, in chloroform) by following step 22(B). i-viii in buffer 5.

42. Perform Dynamic Light Scattering (DLS) analysis on the extruded SUVs to determine their average diameter. Using this value, calculate the vesicles' surface area (assume a perfect sphere, $\left.S_{A}=4 \pi r^{2}\right)$. Use the following formula to convert lipid concentration to $\mathrm{SUV}$ concentration $\left(C_{S U V}\right)$ :

$$
C_{S U V}=\frac{A_{l} C_{l}}{2 S_{A}}
$$

Where $A_{l}=$ area per lipid and $C_{l}=$ lipid concentration. The factor $1 / 2$ accounts for the two leaflets in the lipid bilayer. For POPC, $A_{l}=6.70 \times 10^{-19} \mathrm{~m}^{2}$ (ref. ${ }^{87}$ ).

? TROUBLESHOOTING

43. Repeat steps 8(A) i-v to set up the gel. 
44. Nanopore-SUV binding assay with agarose gel electrophoresis (Steps 44-48). DNA nanobarrel $6 \mathrm{HB}$ containing two cholesterols $(6 \mathrm{HB}-2 \mathrm{C})^{60}$ is used as an example to investigate membrane binding. In addition, a $6 \mathrm{HB}$ without cholesterols $(6 \mathrm{HB}-0 \mathrm{C})$ serves as a negative control. Using six plastic vials $(200 \mu \mathrm{L})$ prepare the following mixtures:

\begin{tabular}{|l|l|l|l|l|l|l|}
\hline $\begin{array}{l}\text { 6HB-2C:SUV } \\
\text { ratio }\end{array}$ & C $\mathrm{SUV} / \mathrm{nM}$ & SUV $/ \mu \mathrm{L}$ & $\begin{array}{l}\mathrm{C}_{6 \mathrm{HB}}-2 \mathrm{C} \\
\mathrm{nM}\end{array}$ & $\begin{array}{l}6 \mathrm{HB}-2 \mathrm{C} / \\
\mu \mathrm{L}\end{array}$ & $\begin{array}{l}\text { Buffer } \\
5 / \mu \mathrm{L}\end{array}$ & $\begin{array}{l}\text { Total } / \\
\mu \mathrm{L}\end{array}$ \\
\hline $1: 0$ & 0.0 & 0.0 & 125 & 5.0 & 35.0 & 40 \\
\hline $1: 300$ & 0.4 & 1.0 & 125 & 5.0 & 34.0 & 40 \\
\hline $1: 120$ & 1.0 & 2.5 & 125 & 5.0 & 32.5 & 40 \\
\hline $1: 60$ & 2.1 & 5.0 & 125 & 5.0 & 30.0 & 40 \\
\hline $1: 30$ & 4.2 & 10.0 & 125 & 5.0 & 25.0 & 40 \\
\hline Control & 14.0 & 33.6 & 0.0 & 0.0 & 6.4 & 40 \\
\hline
\end{tabular}

45. Label all samples and leave to shake for $10 \mathrm{~min}$ at room temperature.

CRITICAL STEP The nanopore:SUV ratio may need to be optimized for the applied DNA nanopores due to differences in binding affinities, the selected lipid anchor, lipid and buffer.

46. Transfer each sample $(15 \mu \mathrm{L})$ to a plastic vial $(200 \mu \mathrm{L})$ and add gel loading dye $(5 \mu \mathrm{L})$, then vortex for $2 \mathrm{~s}$.

47. Load a $100 \mathrm{bp}$ DNA ladder $(5 \mu \mathrm{L})$ into the first lane of the agarose gel. Then load each sample $(20 \mu \mathrm{L})$ into the subsequent lanes.

48. To run and image the gel, repeat step 8(A) viii-ix.

49. Quantifying DNA pore binding to membranes (Steps 49-51). Open ImageJ and load the image of the gel. Use the "Rectangular Selection Tool" to make a selection around the DNA nanopore:SUV 1:0 band (Fig. 10a, blue box). Drag the rectangular selection to below this band (Fig. 10a, grey box) and quantify the background fluorescence intensity using the "Measure" function. Drag the rectangular selection to the next lane (parallel, but to the right of the blue box) and repeat. Repeat for all lanes including the blank (Fig. 10a, 14 nM SUV).

CRITICAL STEP Keep the rectangular selection box size consistent for each lane.

\section{? TROUBLESHOOTING}

50. Select all data and import into Excel. Subtract the background values from the DNA nanopore control and SUV control sample using $I_{6 H B}-I_{\text {background }}$, whereby $I$ is the intensity of the bands. Normalize the data using 6HB-2C:SUV ratio: 1:0 as the lower reference, and Control SUV as the upper reference point.

51. Start the OriginLab software and plot the normalized values against the SUV concentrations. From the analyze drop-down menu, select "Non-Linear Fit", then "Enzyme Kinetics", finally select "Michaelis-Menten". Record the $K_{M}$ value as this is equivalent to the dissociation constant $\left(K_{d}\right)$ in this analysis. 


\begin{tabular}{l} 
Box $3 \mid$ Considerations for sensing molecular transport through DNA-nanopores using \\
conductance measurements \\
\hline DNA is negatively charged due to phosphate groups in the backbone. Nanopores constructed \\
from DNA also have a net negative charge. This characteristic can be exploited to sense \\
molecular transport of small molecules and proteins through the channel. Neutral and \\
negatively charged molecules will diffuse unimpeded through DNA-nanopores in the \\
presence of an electric field. The transport events are typically too fast to detect using \\
existing electrophysiological equipment (dwell times $<66 \mu$ when filtered with a $10 \mathrm{kHz}$ \\
Gaussian low pass filter will not be resolved as distinct blockades ${ }^{88}$ ). However, these \\
transports events may be detected by plotting a power spectrum. Alternatively, the \\
translocation speeds of analytes can be slowed down by causing the analyte to interact with \\
the nanopore. One route is to render the molecules positively charged to facilitate \\
electrostatic interactions with the negatively charged DNA nanopore. The charge state of a \\
protein can be made positive by adjusting the pH of the electrophysiological buffer below \\
its isoelectric point (pI). The resulting ionic interactions can significantly increase the dwell \\
time of protein-pore interactions to allow discreate translocation events to be resolved. An \\
example of protein translocation through a DNA origami pore ${ }^{30}$ is shown in Fig. 12c.
\end{tabular}

52. Setup for single-channel experiments with Orbit 16 (Steps 52-56). Warm the vials of 1,2diphytanoyl-sn-glycero-3-phosphocholine (DPhPC)-octane solution to room temperature before opening (see reagent setup) to prevent water condensation inside the vials. Prepare new lipid solution at least once a week. The lifetime of the lipid solution will also depend on how often the solution is thawed and frozen.

53. Prepare a solution of DNA nanopore and n-octyl-oligo-oxyethylene (OPOE) solution $(0.5 \%, \mathrm{v} / \mathrm{v})$ at a ratio of $2: 1(\mathrm{v} / \mathrm{v})$. Vortex the solution for $5 \mathrm{~s}$.

54. Open the Elements Data Reader (EDR) software and compensate the offset of the Orbit 16 channels using the Orbit 16 test-cell. Adjust the final bandwidth to $10 \mathrm{kHz}$ ( $20 \mathrm{kHz}$ sampling rate, no filter) and the gain range (maximum recording amplitude) to $20 \mathrm{nA}$.

55. Insert the MECA16 chip into the chip holder and the electrode board onto the lid of the chamber.

56. Insert the external bath electrode into the electrode board and attach the electrode board to the Orbit 16 ensuring a tight seal between the board and the MECA16 chip.

57. Planar lipid bilayer formation (Steps 57.-60). Add buffer $10(150 \mu \mathrm{L})$ to the chamber and position the external bath electrode so that it is contact with the buffer. Apply a constant $V_{a p p}$ (usually $+50 \mathrm{mV}$ ).

CRITICAL STEP At this voltage, the current reading should increase upon addition of buffer 10 up to the maximum current of $20 \mathrm{nA}$, as setup in Step iii. This indicates that the microcavities are not blocked and have been filled with the buffer (Fig. 11). In some cases, the current will not increase from $\sim 0 \mathrm{pA}$, which indicates that the microcavities have not been filled with buffer. In this case, using a pipette with a $200 \mu \mathrm{L}$ tip, flush buffer over the cavities to remove air bubbles until the current increases. 
CRITICAL STEP To prepare chips, thoroughly clean with Milli-Q water, then EtOH p.a., and isopropanol, followed by complete drying in nitrogen stream or by heating on a hot plate at less than $60^{\circ} \mathrm{C}$. If the cavities still do not readily wet, fill a single-use $1 \mathrm{ml}$ syringe with buffer, position it normal onto a chip area with the cavities, and press the plunger to force buffer inside the cavities.

\section{? TROUBLESHOOTING}

58. Add the stirrer bar to the chamber and spin it by pressing the dedicated button on the Orbit 16. Ensure that the resting position of the stirrer bar is not directly above the cavities in the middle of the camber. However, the stirrer bar should cross the cavities while spinning. Using a $10 \mu \mathrm{L}$ pipette, dip the tip into the DPhPC-octane solution without aspirating any solution. This should result in the uptake of a very small amount of DPhPC-octane into the tip of the pipette. Eject the lipid solution onto the surface of the MECA16 chip in the vicinity of the cavity array. Deposit the lipid at a position to allow the stir bar to move over the lipid, pick it up, and spread it over the cavities in the middle of the chip upon rotation.

59. Initially stir the solution between 50-100 rpm to evenly spread the lipid solution on the chip's surface. Then reduce the stirring speed to $<10 \mathrm{rpm}$. This will promote bilayer formation over the microcavities, as indicated by the current signal dropping back to $0 \mathrm{pA}$ at a constantly applied voltage.

CRITICAL STEP If bilayers are not forming, repeat steps vii and viii| several times until the current signal displays $0 \mathrm{pA}$ in all channels. Caution should be taken, as addition of too much $\mathrm{DPhPC}$-octane solution can lead to thick multi-layered membranes, which are not desired as they cannot be spanned by nanopores.

60. Using the "Zap" function of the EDR software break the membranes and reform them by stirring at a low rpm. Repeat this step 1-2 times to ensure only thin, single-layer bilayers have formed.

\section{? TROUBLESHOOTING}

61. Monitoring DNA nanopore insertions (Steps 61-66). Ensure that the bilayers are stable by observing the current signals for a few min at applied transmembrane voltage. The occurrence of current fluctuations or increases up to the resolution limit are characteristic of instable membranes or completely open microcavities (Fig. 11). Any broken membranes can be reformed by rotating the stir bar at low rpm without addition of any further lipid.

CRITICAL STEP If membranes will not form in some of the microcavities, it is important to turn these channels off using the EDR software. This ensures that the signal in these cavities will not interfere with any current measurements in the other cavities.

62. Once the membranes are stable, add the nanopore:OPOE solution $(1-2 \mu \mathrm{L})$ to the chamber close to the surface of the chip. Some of the membranes may rupture due to exposure of the lipid bilayers to detergent. At this stage, either turn off the corresponding channels via the EDR software, or reform the membranes by re-spreading the lipid with the stir-bar.

\section{? TROUBLESHOOTING}

63. Spontaneous DNA nanopore insertions will be observed as characteristic increases of defined amplitude in the current signal (Fig. 11). In most cases, current will be stable, with intermittent reductions in current towards $0 \mathrm{pA}$, particularly at high voltages which cause subconductance states (Fig. 12a), depending on the DNA pore. If no insertions have occurred after 
$10 \mathrm{~min}$, gently stir the solution with a pipette (pipette tip facing away from the membranes) or repeat step xi. Breaking and reforming the membranes can aid in nanopore insertions, as can alternating $V_{a p p}$, between positive and negative potentials.

64. Once a stable DNA nanopore has inserted, start recording. $V_{a p p}$ can be altered in steps to characterize the conductance properties of the DNA nanopore at various applied potentials. Using the EDR software, protocols can be run to obtain voltage-steps where the voltage is held for a set time before switching to the next voltage, or ramps where the voltage increases linearly with time. These can be used to obtain current-voltage (IV) curves (Fig. 12b) that are routinely used as a way to display nanopore conductance characteristics in research manuscripts.

65. Once enough data has been collected for the pore, rupture the membrane using the "Zap" function of the EDR software and stop recording. Repeat steps x-xiii to obtain the same data for at least 15-20 independent pore insertions. This ensures that any conductance characteristics can be observed and accounted for with statistical significance.

66. Once measurements have been completed, remove the electrophysiological buffer using a $200 \mu \mathrm{L}$ pipette. Clean the chip, stir-bar and bath electrode using water and ethanol, before drying under a stream of nitrogen.

67. Data processing for single-channel current recordings (Steps 67-72). Install and open data using Clampfit software. Use Fig. 12 as a reference for all following steps to present raw current-voltage data.

68. Produce an all-point conductance histogram. Move "Cursor 1" to the start and "Cursor 2" to the end of the dataset. Choose "Histogram" from the "Analyze" menu. Alter the "Bin Width" to the desired size and change the "Region" to "Process" between cursors 1 and 2. Press "OK" to produce an "All-Point Frequency Histogram". The individual data points can be found under the "Results" tab.

69. Produce an IV curve (steps 69-71). Move "Cursor 1" to the start and "Cursor 2" to the end of the voltage ramp. In Fig. 12b this starts at $-150 \mathrm{mV}$. Chose the "Statistics" option under the "Analyze" tab. Change the "Region" to "Process" between cursors 1 and 2 and ensure only the "Mean (Units)" box is ticked. Press "OK" to analyze the average current and voltage between cursors 1 and 2. The results can be viewed by selecting the "Results" tab.

70. Repeat step 69 for each voltage and plot the resulting current against voltage to produce an IV curve.

71. Determine the unitary pore conductance $(\mathrm{Q})$ from the gradient of the line.

72. Analyze small molecule translocation events through the pore. Move "Cursor 1" to the start of the data to be analysed and "Cursor 2" to the end. Chose the "Single-Channel Search" option under the "Event Detection" menu. Ensure the "Level 0" line is on 0 and the "Search Region" is between cursors 1 and 2. Press "OK", then choose the "Non-stop" option of the "SingleChannel Search". The resulting dwell time and current amplitude data analysis can be found in the "Results" tab. Plot the percentage amplitude block against the dwell time on a logarithmic scale. 


\section{Dye flux assays to confirm pore activity • TIIMING 2 d}

73. Preparation of small unilamellar vesicles (SUVS) (steps 73-76). Add 1,2-dioleoyl-snglycero-3-phosphocholine (DOPC, $70 \mu \mathrm{L}, 10 \mathrm{mM}$, in chloroform) and 1,2-dioleoyl-snglycero-3-phosphoethanolamine (DOPE, $30 \mu \mathrm{L}, 10 \mathrm{mM}$, in chloroform) in a 7:3 ratio to a round bottom flask $(5 \mathrm{~mL})$ and use a rotary evaporator to remove the solvent for $20 \mathrm{~min}$. This results in the formation of a dry lipid film on the walls of the round bottom flask.

74. Attach the round bottom flask with the dry lipid film to a high vacuum line and leave to dry for $1 \mathrm{~h}$.

CRITICAL STEP The chloroform must be completely removed from the sample.

75. Add buffer $11(1 \mathrm{~mL})$ and vortex for $3 \times 10 \mathrm{~s}$. Then place in a bath-sonicator for $20 \mathrm{~min}$ at $30{ }^{\circ} \mathrm{C}$ to form the vesicles.

! CAUTION Sonication uses high energy sound waves. Use a float or clamp system to support the round bottom flask. Never immerse your fingers in the water bath when sonication is on.

76. Transfer the SUV suspension with encapsulated SRB dye (SRB-SUVs, $1 \mathrm{~mL}$ ) to a plastic vial $(1.5 \mathrm{~mL})$ and store at $4{ }^{\circ} \mathrm{C}$ overnight.

77. Vesicle purification. Set-up a NAP-25 column and run buffer $5(3 \times 5 \mathrm{~mL})$ through the column. Then load the SRB-SUV suspension $(1 \mathrm{~mL})$ onto the column. Then add buffer 5 (3 $\mathrm{mL}$ ) and collect the eluent in fractions $(300 \mu \mathrm{L})$. The SRB-SUVs (pink) will elute first followed by free SRB (dark purple).

78. Switch on the fluorescence spectrophotometer. CRITICAL STEP Wash cuvettes with water followed by ethanol, and then dry thoroughly before use.

79. Confirming the self-quenching properties of the encapsulated SRB (Steps 79-80). Add buffer $5(100 \mu \mathrm{L})$ and the purified SRB-SUVs $(10 \mu \mathrm{L})$ to the cuvette. Place the cuvette in the cell changer of the fluorescence spectrophotometer and perform a fluorescence scan (see Equipment Set-Up). Add Triton X-100 $(10 \mu \mathrm{L})(1 \%(\mathrm{v} / \mathrm{v})$ to rupture the SUVs and release the quenched dye. Repeat with all fractions cleaning the cuvette each time. Combine the fractions that show the maximum increase in fluorescence intensity upon rupturing. CRITICAL STEP If only a small increase is observed upon Triton X-100 addition, discard the vesicles and repeat steps i-vii.

\section{? TROUBLESHOOTING}

80. Set-up the kinetics software to monitor the DNA nanopores-mediated SRB release over time (see Equipment Set-Up). Dilute the SRB-SUVs $(10 \mu \mathrm{L})$ into buffer $5(110 \mu \mathrm{L})$ and transfer to a cuvette. Place the cuvette in the cell changer and commence the kinetic run.

81. Dye release assay (Steps 81-83). Allow the solution to stand for at least $5 \mathrm{~min}$ to confirm no dye leakage occurs, then add the nanopore $(30 \mu \mathrm{L}, 1 \mu \mathrm{M})$ and mix the solution. 
CRITICAL STEP The exact amounts of pore needed will vary depending on the structure used. This will require some experimental investigation.

\section{? TROUBLESHOOTING}

82. Add Triton X-100 (10 $\mu \mathrm{L}, 1 \%(\mathrm{v} / \mathrm{v}))$ after $1 \mathrm{~h}$ and mix. Allow the signal to stabilize for 5 $\min$.

CRITICAL STEP Addition of Triton X-100 should lyse all vesicle and provide the maximum value of release allowing different runs to be compared.

83. Repeat all runs in triplicate, including controls without cholesterol lipid anchors.

CRITICAL STEP 6-Carboxyfluorescein (CF) can be used as a negative control. This dye has a net charge of -3 and does not pass through the negatively charged $6 \mathrm{HB}$ pore under these conditions. Use $50 \mathrm{mM} \mathrm{CF}$ in place of $50 \mathrm{mM}$ SRB in buffer 11 . An example trace for the CF release assay are displayed in Fig. 13.

84. Data processing for the SRB dye flux assay (Steps 84-86). Import kinetic fluorescence data into OriginLab software, making a separate worksheet for each assay (name this "RAW data + name of assay") leaving two empty columns between each run. For runs performed in triplicate, this will result in time being placed in column $\mathrm{A}(\mathrm{Col}(\mathrm{A}))$ and the data from Run 1 in $\mathrm{Col}(\mathrm{B})$. For run 2 this will be $\operatorname{Col}(\mathrm{E})$ and $\operatorname{Col}(\mathrm{F})$, respectively and for run 3 this will be $\mathrm{Col}(\mathrm{I})$ and Col(J). From the column drop down menu, select "Set Column As" and set Col(A), Col(E), and Col(I) to variable X.

85. From the column menu, duplicate the worksheet by selecting "Duplicate" then "Duplicate Without Data" (name this "Processed data + name of assay"). Set the time to start at time $=0$ $(\mathrm{t}=0)$ by placing a 0 in the first row of each of $\operatorname{Col}(\mathrm{A}), \operatorname{Col}(\mathrm{E})$, and $\operatorname{Col}(\mathrm{I})$. Then select the time data from the RAW data sheet and paste into the relevant column.

86. From the RAW data sheet, select all data after 5 min so that the data point at time $=0$ is the first point following nanopore addition. Paste this into the relevant column of the "Processed data" sheet.

87. Normalization (Steps 87-90). In the next column of the "Processed Data" sheet (for run 1 this will be $\operatorname{Col}(\mathrm{C})$ ) subtract the value at $\mathrm{t}=0$ from the data set. Do this by selecting "Set Column Values" from the column dropdown menu and set $\mathrm{Col}(\mathrm{C})=\mathrm{Col}(\mathrm{B})$ - (the value at $\mathrm{t}=$ $0)$. Repeat this for $\operatorname{Col}(\mathrm{G})$ and $\operatorname{Col}(\mathrm{K})$. The first row of each run should now be $(0,0)$.

88. Select $\mathrm{Col}(\mathrm{C})$ and right click on the column. Select Normalize. In the pop-up window select "Divide by MAX" from the method and select Col(D) as the output. The data should now be normalized between $0-1$. Repeat this for all other runs.

89. If no columns remain, add a new one. From the dropdown menu select "Set Column Values". Set $\operatorname{Col}(\mathrm{M})=(\mathrm{Col}(\mathrm{D})+\operatorname{Col}(\mathrm{H})+\mathrm{Col}(\mathrm{L})) / 3$. This will average all of the normalized runs.

90. Repeat steps 84-89 for all remaining assays. An example trace for the SRB release assay are displayed in Fig. 13. 


\section{Timing}

Step 1: Nanopore design:

Option (A): Nanopore designs using the nanobarrel method. 1 - $3 \mathrm{~d}$,

Option (B): Nanopore design using DNA origami. 1 - $7 \mathrm{~d}$

Steps 2-5: Predicting nanopore structural dynamics using CanDo's online service

Step 6: Introducing lipid anchors

Option (A): Cholesterol lipid anchors. $1 \mathrm{~d}$,

Option (B): Alkyl lipid anchors. 1-3 d.

Step 7: Nanopore assembly:

Option (A): Assembly of nanobarrel pores. $3 \mathrm{~h}$,

Option (B): Assembly of DNA origami pores. 1-8 d

Step 8: Gel electrophoresis characterization:

Option (A): Agarose gel electrophoresis. 2-3 h,

Option (B): PAGE. 2-3 h

Step 9: Purification:

Option (A): Gel extraction. 1-2 d,

Option (B): PEG precipitation. 1-2 d,

Option (C): Size Exclusion Chromatography (SEC). 4 h,

Steps 10-16: Determining nanopore concentration after purification. $10 \mathrm{~min}$

Steps 17-27: Sample preparation and imaging with transmission electron microscopy

(TEM). $1 \mathrm{~d}$

Option (A): Preparation of TEM samples without membranes. $\sim 1 \mathrm{~h}$

Option (B): Preparation of TEM samples for cholesterol-modified DNA origami pores

inserted into SUVs. $\sim 3 \mathrm{~h}$

Steps 27-40: Sample preparation and imaging with atomic force microscopy (AFM) . $1 \mathrm{~d}$

Option (A): Adhering DNA nanostructures on mica. 10 min

Option (B): Adhering DNA nanostructures to mica-supported lipid bilayers. $\sim 2 \mathrm{~h}$

Steps 41-51: Gel assay to determine pore-membrane binding. $4 \mathrm{~h}$

Steps 52-72: Single-channel current recordings using the Orbit16 recording kit. 6 h

Steps 73-90: Dye flux assays to confirm pore activity. 2 d

\section{TROUBLESHOOTING}

See Table 5 for troubleshooting guidance.

Table 5| Troubleshooting table

\begin{tabular}{llll}
\hline Step & Problem & Possible reason & Solution \\
\hline 4 & $\begin{array}{l}\text { Predicted high } \\
\text { nanostructure } \\
\text { flexibility }\end{array}$ & $\begin{array}{l}\text { Low structural } \\
\text { stability }\end{array}$ & $\begin{array}{l}\text { Increase duplex length; introduce } \\
\text { more G-C base pairs; refine position } \\
\text { or add additional crossovers between } \\
\text { DNA layers }\end{array}$ \\
\hline $\begin{array}{l}\text { 7(A)ivan } \\
\text { d 7(B)iv }\end{array}$ & $\begin{array}{l}\text { Unsuccessful } \\
\text { nanopore } \\
\text { assembly }\end{array}$ & $\begin{array}{l}\text { Optimise annealing } \\
\text { conditions; } \\
\text { purification required; } \\
\text { degradation of DNA } \\
\text { strands }\end{array}$ & $\begin{array}{l}\text { Increase monovalent cation } \\
\text { concentration or add divalent cations } \\
\text { e.g. 10-30 mM } \mathrm{MgCl}_{2} \text { and vary } \\
\text { annealing rate, e.g. } 1-60 \text { min per }\end{array}$ \\
& & $\begin{array}{l}{ }^{\circ} \mathrm{C} ; \\
\text { purify structure (see step 9); aliquot } \\
\text { DNA and keep frozen until required }\end{array}$ \\
\hline 7B(ii) & Unsure & & $\begin{array}{l}\text { Depends upon location of cholesterol } \\
\text { strands and method of purification. If }\end{array}$
\end{tabular}




\begin{tabular}{|c|c|c|c|}
\hline & $\begin{array}{l}\text { cholesterol } \\
\text { strands before } \\
\text { folding or after } \\
\text { purification }\end{array}$ & & $\begin{array}{l}\text { the cholesterol binding overhangs are } \\
\text { inaccessible, add cholesterol strands } \\
\text { before folding. Cholesterol } \\
\text { modifications can interfere with } \\
\text { purification so this must be } \\
\text { considered. }\end{array}$ \\
\hline $\begin{array}{l}8(\mathrm{~A}) \mathrm{vii} \\
\text { and } \\
8(\mathrm{~B}) \mathrm{iii}\end{array}$ & $\begin{array}{l}\text { Nanopore } \\
\text { aggregates } \\
\text { when lipid } \\
\text { anchors added }\end{array}$ & $\begin{array}{l}\text { Strong hydrophobic } \\
\text { intermolecular } \\
\text { interactions between } \\
\text { lipid anchors }\end{array}$ & $\begin{array}{l}\text { Add surfactant to disrupt aggregates, } \\
\text { e.g. } 1.5 \%(\mathrm{v} / \mathrm{v}) \text { OPOE; incubate } \\
\text { solution at higher temperatures, e.g. } \\
30-45^{\circ} \mathrm{C} \text {; for DNA origami pores add } \\
\text { lipid anchors after folding and } \\
\text { purification; vary lipid anchor strand } \\
\text { ratio }\end{array}$ \\
\hline $9(\mathrm{C}) \mathrm{x}$ & $\begin{array}{l}\text { Excess staples } \\
\text { co-elute with } \\
\text { folded origami }\end{array}$ & $\begin{array}{l}\text { Poor separation } \\
\text { between folded } \\
\text { nanostructure and } \\
\text { excess staples }\end{array}$ & $\begin{array}{l}\text { Reduce flow rate (step vi) to improve } \\
\text { separation, e.g. } 0.25 \mathrm{~mL} \text { per min }\end{array}$ \\
\hline 26 & $\begin{array}{l}\text { Poor TEM } \\
\text { imaging }\end{array}$ & $\begin{array}{l}\text { Not optimised } \\
\text { staining conditions }\end{array}$ & $\begin{array}{l}\text { Increase plasma cleaning time; } \\
\text { increase DNA nanostructure-grid } \\
\text { incubation time; vary uranyl staining } \\
\text { duration; centrifuge uranyl staining } \\
\text { solution, e.g. } 10,000 \mathrm{x} \text { g for } 10 \mathrm{~min}\end{array}$ \\
\hline 40 & $\begin{array}{l}\text { Poor AFM } \\
\text { imaging }\end{array}$ & $\begin{array}{l}\text { Blunt cantilever tip; } \\
\text { DNA nanostructure } \\
\text { does not adhere to } \\
\text { mica surface; DNA } \\
\text { nanostructure } \\
\text { diffuses on mica } \\
\text { surface }\end{array}$ & $\begin{array}{l}\text { Replace cantilever; purify excess } \\
\text { staple strands; add } 0.01 \% \text { poly-L- } \\
\text { lysine solution to mica first, wash } \\
\text { surface multiple times, then add DNA } \\
\text { nanostructure }\end{array}$ \\
\hline $\begin{array}{l}42 \text { and } \\
74\end{array}$ & $\begin{array}{l}\text { Vesicles not } \\
\text { forming }\end{array}$ & $\begin{array}{l}\text { Lipids have } \\
\text { deteriorated; residual } \\
\text { chloroform present } \\
\end{array}$ & $\begin{array}{l}\text { Aliquot lipids and keep frozen until } \\
\text { required; ensure vacuum pump is } \\
\text { working properly }\end{array}$ \\
\hline 49 & $\begin{array}{l}\text { Nanopores do } \\
\text { not show } \\
\text { binding } \\
\text { vesicles }\end{array}$ & $\begin{array}{l}\text { Negatively charged } \\
\text { lipid used; SUV } \\
\text { concentration too } \\
\text { low; degradation of } \\
\text { lipid anchor strands; } \\
\text { toe-hold extensions } \\
\text { not accessible; lipid } \\
\text { anchor strands } \\
\text { aggregated; duplex } \\
\text { not sufficiently } \\
\text { stable }\end{array}$ & $\begin{array}{l}\text { Use neutral lipids or decrease content } \\
\text { of negatively charged lipid; increase } \\
\text { SUV concentration; aliquot lipid } \\
\text { anchor modified-oligonucleotides and } \\
\text { keep frozen until required; for DNA } \\
\text { origami add excess lipid modified } \\
\text { strands and incubate at higher } \\
\text { temperatures; increase length of } \\
\text { duplex sequences and G-C base pair } \\
\text { content }\end{array}$ \\
\hline 49 & $\begin{array}{l}\text { Nanopores } \\
\text { shows non- } \\
\text { specific } \\
\text { binding to } \\
\text { membranes }\end{array}$ & $\begin{array}{l}\text { Ionic interactions } \\
\text { between DNA, lipid } \\
\text { headgroups and } \\
\text { divalent metal ions } \\
\text { resulting in non- } \\
\text { specific interactions }\end{array}$ & $\begin{array}{l}\text { Reduce divalent metal ion } \\
\text { concentration, or introduce } \\
\text { monovalent ions, e.g. } 300 \mathrm{mM} \mathrm{KCl} \\
\text { (i.e. buffer 5) }\end{array}$ \\
\hline
\end{tabular}




\begin{tabular}{|c|c|c|c|}
\hline 57 & $\begin{array}{l}\text { Chambers do } \\
\text { not fill with } \\
\text { buffer }\end{array}$ & $\begin{array}{l}\text { Air bubble trapped } \\
\text { in MECA16 chip } \\
\text { cavity }\end{array}$ & $\begin{array}{l}\text { Gently disrupt bubble using syringe } \\
\text { plunger; sonicate chip in buffer } 10 \text { for } \\
3 \mathrm{~s}\end{array}$ \\
\hline 60 & $\begin{array}{l}\text { Membranes do } \\
\text { not break using } \\
\text { "Zap function" }\end{array}$ & $\begin{array}{l}\text { Chamber-covered } \\
\text { membrane is } \\
\text { multiple bilayers } \\
\text { thick }\end{array}$ & $\begin{array}{l}\text { Dislodge using pipettor by blowing air } \\
\text { bubbles across surface using a pipette }\end{array}$ \\
\hline 62 & $\begin{array}{l}\text { Membranes } \\
\text { will not stably } \\
\text { form or break }\end{array}$ & $\begin{array}{l}\text { High detergent } \\
\text { concentration; low } \\
\text { lipid concentration; } \\
\text { lipids have oxidised }\end{array}$ & $\begin{array}{l}\text { Reduce detergent concentration; add } \\
\text { more lipid solution to chamber; aliquot } \\
\text { lipid and keep frozen until required }\end{array}$ \\
\hline 79 & $\begin{array}{l}\text { Small or no } \\
\text { change in } \\
\text { fluorescence } \\
\text { upon addition } \\
\text { of surfactant }\end{array}$ & $\begin{array}{l}\text { No vesicles present } \\
\text { in fraction; vesicles } \\
\text { unstable; } \\
\text { degradation of SRB }\end{array}$ & $\begin{array}{l}\text { Test other fractions; remake vesicles; } \\
\text { use fresh laser grade SRB }\end{array}$ \\
\hline 81 & $\begin{array}{l}\text { Fluorescence } \\
\text { emission } \\
\text { erratic }\end{array}$ & $\begin{array}{l}\text { Heterogenous } \\
\text { vesicle solution; } \\
\text { vesicles aggregating }\end{array}$ & $\begin{array}{l}\text { Mix solution in cuvette and equilibrate } \\
\text { for } 5 \text { min; stir solution with magnetic } \\
\text { stirrer bar (if applicable) }\end{array}$ \\
\hline 81 & $\begin{array}{l}\text { Vesicles are } \\
\text { leaking }\end{array}$ & $\begin{array}{l}\text { The solution is not } \\
\text { osmotically } \\
\text { balanced; lipids have } \\
\text { oxidized }\end{array}$ & $\begin{array}{l}\text { Calculate the osmoles inside and } \\
\text { outside the vesicles. If unbalanced, } \\
\text { adjust buffer } 5 \text { until balanced (this } \\
\text { may depend on nanopore folding } \\
\text { buffer); aliquot lipid and keep frozen } \\
\text { until required }\end{array}$ \\
\hline 81 & $\begin{array}{l}\text { Internal dye } \\
\text { fluorescence } \\
\text { does not } \\
\text { increase upon } \\
\text { nanopore } \\
\text { addition }\end{array}$ & $\begin{array}{l}\text { Multi-lamellar } \\
\text { vesicles present; } \\
\text { incorrect purified } \\
\text { fraction used; } \\
\text { nanopores not } \\
\text { correctly inserted in } \\
\text { high ratios; nanopore } \\
\text { not correctly folded }\end{array}$ & $\begin{array}{l}\text { Use a protein pore as a positive } \\
\text { control, e.g. } \alpha \text {-Hemolysin; re-extrude } \\
\text { vesicles; ensure only fractions } \\
\text { displaying } 8 \text {-10x increase upon } \\
\text { surfactant induced lysis are used; vary } \\
\text { nanopore concentration; increase } \\
\text { number of lipid anchors; incubate at } \\
\text { higher temperatures, e.g. } 30-45^{\circ} \mathrm{C} \text {; } \\
\text { reduce concentration of divalent } \\
\text { cations; add detergent to form } \\
\text { nanopore-micelle prior to vesicle } \\
\text { incubation; confirm nanopore } \\
\text { correctly folded }\end{array}$ \\
\hline
\end{tabular}

\section{Anticipated results}

Pores designed using the methods described can be seen in Fig. 2 and Fig. 3. Examples of gel electrophoretic analysis using the nanobarrel and origami designs as well as different degrees of cholesterol functionalization are shown in Fig. 8. TEM pictures of a six helical bundle are shown in Fig. 9a-b, a DNA origami nanopore is displayed in 9c and a DNA origami bound to an SUV is shown in 9d. Fig. 10 contains in panel (a) an agarose gel on the titration of pore binding to SUVs and in panel (b) and the analysis of the gel-based titration. Finally, an example release curve for the SRB and CF dye release are shown in Fig. 13. 
Single-channel conductance measurements. The typical unitary conductance values of individual nanopores should correspond to theoretical values calculated using the equation ${ }^{30}$ :

$$
G=\kappa \frac{\pi d^{2}}{4 L+\pi d}
$$

Where $\kappa$ is the electrical conductivity (equal to $10.86 \mathrm{Sm}^{-1}$ for $1 \mathrm{M} \mathrm{KCl}$ at $25{ }^{\circ} \mathrm{C}$ ), $d$ is the predicted diameter of the pore and $L$ the length of the pore. However, this simple calculation should only be used as a rough guide for conductance predictions, as it assumes a constant mobility of electrolyte ions in negatively charged nanopores. Using the $6 \mathrm{HB}$ pore ${ }^{22}$ as an example, this calculation predicts a conductance of $3.2 \mathrm{nS}$. However, the experimentally determined conductance is $1.6 \mathrm{nS}$. DNA nanopores could also display stochastic gating behaviour (Fig. 12a), particularly at high voltages, whereby the channel conductance fluctuates between distinct sub-states. These sub-states can be analyzed using an all-point histogram (Fig. 12a). Translocation events for molecules can be detected by comparing channel conductance before and after addition of the molecule. Translocation will be detected as transient current blockage events displaying dwell times that vary with the affinity to the pore. Independent of affinity, the frequency of events will increase with the concentration of the molecule in the chamber ${ }^{30}$.

\section{Acknowledgements}

The authors would like to thank Jonah Ciccone, Rachael Dickman and Helena Philpott for helping with figures and providing valuable feedback. Furthermore, the authors thank Conrad Weichbrodt from Nanion Technologies GmbH for providing feedback on the section on single channel current recordings. The Howorka Group receives funding from the EPSRC (EP/ N009282/1), the BBSRC (BB/M025373/1, BB/N017331/1), and the Leverhulme Trust (RPG2017-015). Conor Lanphere and Elena Georgiou are supported by the Biotechnology and Biological Sciences Research Council (grant number: BB/MO09513/1). Conor Lanphere is also supported by the National Physical Laboratory.

\section{Author contributions}

C.L., D.O.S., G.P., and J.R.B. provided the protocols for design and assembly. D.O.S. and G.P. supplied the protocol for CanDo. C.L., D.O.S, X.Y.Z. and J.R.B. prepared the protocol for cholesterol lipid anchors. J.R.B. contributed the protocol for the alkyl modification of DNA. C.L. and D.O.S. generated the protocol for gel electrophoretic characterization. E.G. prepared the protocols for purification of DNA origami structures. Y.X. provided the protocols for TEM analysis and J.R.B. provided the protocols for AFM. C.L. provided the protocol for gel binding assays. A.D. wrote the protocol for single-channel current recordings. C.L. provided the protocol for dye flux assays. D.O.S. compiled the list and set up of materials and equipment. C.L., A.D., and J.R.B supplied the troubleshooting steps. C.L., D.O.S., J.R.B and S.H. wrote the manuscript with input from all authors. C.L., D.O.S, J.R.B. and S.H. edited the manuscript. C.L., A.D., G.P., and J.R.B., generated the figures and J.R.B. edited them. All authors were part of the data analysis and discussions.

\section{Competing Financial Interests}

G.P., J.R.B., and S.H. hold patents on DNA nanopores which have been licensed to Oxford Nanopore Technologies. All other authors declare no competing interests. 


\section{Data availability statement}

All data is available from the corresponding author upon reasonable request.

\section{References}

1. Tunuguntla, R. H., Allen, F. I., Kim, K., Belliveau, A. \& Noy, A. Ultrafast proton transport in sub-1-nm diameter carbon nanotube porins. Nat. Nanotechnol. 11, 639644 (2016).

2. Feng, J., Liu, K., Bulushev, R. D., Khlybov, S., Dumcenco, D., Kis, A. \& Radenovic, A. Identification of single nucleotides in mos2 nanopores. Nat. Nanotechnol. 10, 1070-1076 (2015).

3. Yusko, E. C., Bruhn, B. R., Eggenberger, O. M., Houghtaling, J., Rollings, R. C., Walsh, N. C., Nandivada, S., Pindrus, M., Hall, A. R., Sept, D., Li, J., Kalonia, D. S. \& Mayer, M. Real-time shape approximation and fingerprinting of single proteins using a nanopore. Nat. Nanotechnol. 12, 360-367 (2017).

4. Huang, G., Voet, A. \& Maglia, G. Frac nanopores with adjustable diameter identify the mass of opposite-charge peptides with 44 dalton resolution. Nat. Commun. 10, 835 (2019).

5. Wei, R. S., Gatterdam, V., Wieneke, R., Tampe, R. \& Rant, U. Stochastic sensing of proteins with receptor-modified solid-state nanopores. Nat. Nanotechnol. 7, 257-263 (2012).

6. Thakur, A. K. \& Movileanu, L. Real-time measurement of protein-protein interactions at single-molecule resolution using a biological nanopore. Nat Biotechnol 37, 96-101 (2019).

7. Pulcu, G. S., Mikhailova, E., Choi, L. S. \& Bayley, H. Continuous observation of the stochastic motion of an individual small-molecule walker. Nat. Nanotechnol. 10, 7683 (2015).

8. Miles, B. N., Ivanov, A. P., Wilson, K. A., Dogan, F., Japrung, D. \& Edel, J. B. Single molecule sensing with solid-state nanopores: Novel materials, methods, and applications. Chem. Soc. Rev. 42, 15-28 (2013).

9. Varongchayakul, N., Song, J., Meller, A. \& Grinstaff, M. W. Single-molecule protein sensing in a nanopore: A tutorial. Chem. Soc. Rev. 47, 8512-8524 (2018).

10. Alberts, B., Johnson, A., Lewis, J., Morgan, D., Raff, M., Roberts, K. \& Walter, P. Molecular biology of the cell, sixth edition. (Garland Publishing, 2014).

11. Quick, J., Loman, N. J., Duraffour, S., Simpson, J. T., Severi, E., Cowley, L., Bore, J. A., Koundouno, R., Dudas, G., Mikhail, A., Ouedraogo, N., Afrough, B., Bah, A., Baum, J. H., Becker-Ziaja, B., Boettcher, J. P., Cabeza-Cabrerizo, M., CaminoSanchez, A., Carter, L. L., Doerrbecker, J., Enkirch, T., Garcia-Dorival, I., Hetzelt, N., Hinzmann, J., Holm, T., Kafetzopoulou, L. E., Koropogui, M., Kosgey, A., Kuisma, E., Logue, C. H., Mazzarelli, A., Meisel, S., Mertens, M., Michel, J., Ngabo, D., Nitzsche, K., Pallasch, E., Patrono, L. V., Portmann, J., Repits, J. G., Rickett, N. Y., Sachse, A., Singethan, K., Vitoriano, I., Yemanaberhan, R. L., Zekeng, E. G., Racine, T., Bello, A., Sall, A. A., Faye, O., Faye, O., Magassouba, N., Williams, C. V., Amburgey, V., Winona, L., Davis, E., Gerlach, J., Washington, F., Monteil, V., Jourdain, M., Bererd, M., Camara, A., Somlare, H., Camara, A., Gerard, M., Bado, G., Baillet, B., Delaune, D., Nebie, K. Y., Diarra, A., Savane, Y., Pallawo, R. B., Gutierrez, G. J., Milhano, N., Roger, I., Williams, C. J., Yattara, F., Lewandowski, K., Taylor, J., Rachwal, P., Turner, D. J., Pollakis, G., Hiscox, J. A., Matthews, D. A., 
O'Shea, M. K., Johnston, A. M., Wilson, D., Hutley, E., Smit, E., Di Caro, A., Wolfel, R., Stoecker, K., Fleischmann, E., Gabriel, M., Weller, S. A., Koivogui, L., Diallo, B., Keita, S., Rambaut, A., Formenty, P., Gunther, S. \& Carroll, M. W. Real-time, portable genome sequencing for ebola surveillance. Nature 530, 228-232 (2016).

12. Majd, S., Yusko, E. C., Billeh, Y. N., Macrae, M. X., Yang, J. \& Mayer, M. Applications of biological pores in nanomedicine, sensing, and nanoelectronics. Curr Opin Biotechnol 21, 439-476 (2010).

13. Galenkamp, N. S., Soskine, M., Hermans, J., Wloka, C. \& Maglia, G. Direct electrical quantification of glucose and asparagine from bodily fluids using nanopores. Nat. Commun. 9, 4085 (2018).

14. Howorka, S. Building membrane nanopores. Nat. Nanotechnol. 12, 619-630 (2017).

15. Clarke, J., Wu, H. C., Jayasinghe, L., Patel, A., Reid, S. \& Bayley, H. Continuous base identification for single-molecule nanopore DNA sequencing. Nat. Nanotechnol. 4, 265-270 (2009).

16. Cherf, G. M., Lieberman, K. R., Rashid, H., Lam, C. E., Karplus, K. \& Akeson, M. Automated forward and reverse ratcheting of DNA in a nanopore at 5-angstrom precision. Nat Biotechnol 30, 344-348 (2012).

17. Manrao, E. A., Derrington, I. M., Laszlo, A. H., Langford, K. W., Hopper, M. K., Gillgren, N., Pavlenok, M., Niederweis, M. \& Gundlach, J. H. Reading DNA at single-nucleotide resolution with a mutant mspa nanopore and phi29 DNA polymerase. Nat. Biotechnol. 30, 349-353 (2012).

18. Mahendran, K. R., Niitsu, A., Kong, L., Thomson, A. R., Sessions, R. B., Woolfson, D. N. \& Bayley, H. A monodisperse transmembrane alpha-helical peptide barrel. Nat. Chem. 9, 411-419 (2017).

19. Gopfrich, K., Li, C. Y., Mames, I., Bhamidimarri, S. P., Ricci, M., Yoo, J., Mames, A., Ohmann, A., Winterhalter, M., Stulz, E., Aksimentiev, A. \& Keyser, U. F. Ion channels made from a single membrane-spanning DNA duplex. Nano Lett. 16, 46654669 (2016).

20. Gopfrich, K., Zettl, T., Meijering, A. E., Hernandez-Ainsa, S., Kocabey, S., Liedl, T. \& Keyser, U. F. DNA-tile structures induce ionic currents through lipid membranes. Nano Lett. 15, 3134-3138 (2015).

21. Langecker, M., Arnaut, V., Martin, T. G., List, J., Renner, S., Mayer, M., Dietz, H. \& Simmel, F. C. Synthetic lipid membrane channels formed by designed DNA nanostructures. Science 338, 932-936 (2012).

22. Burns, J. R., Seifert, A., Fertig, N. \& Howorka, S. A biomimetic DNA-based channel for the ligand-controlled transport of charged molecular cargo across a biological membrane. Nat. Nanotechnol. 11, 152-156 (2016).

23. Burns, J., Stulz, E. \& Howorka, S. Self-assembled DNA nanopores that span lipid bilayers. Nano Lett. 13, 2351-2356 (2013).

24. Seifert, A., Göpfrich, K., Burns, J. R., Fertig, N., Keyser, U. F. \& Howorka, S. Bilayer-spanning DNA nanopores with voltage-switching between open and closed state. ACS Nano 9, 1117-1126 (2015).

25. Arnott, P. M., Joshi, H., Aksimentiev, A. \& Howorka, S. Dynamic interactions between lipid-tethered DNA and phospholipid membranes. Langmuir 34, 1508415092 (2018).

26. Kuzuya, A., Wang, R., Sha, R. \& Seeman, N. C. Six-helix and eight-helix DNA nanotubes assembled from half-tubes. Nano Lett. 7, 1757-1763 (2007).

27. Chen, L., Liang, S., Chen, Y., Wu, M. \& Zhang, Y. Destructing the plasma membrane with activatable vesicular DNA nanopores. ACS Appl. Mater. Interfaces 12, 96-105 (2020). 
28. Gopfrich, K., Li, C. Y., Ricci, M., Bhamidimarri, S. P., Yoo, J., Gyenes, B., Ohmann, A., Winterhalter, M., Aksimentiev, A. \& Keyser, U. F. Large-conductance transmembrane porin made from DNA origami. ACS Nano 10, 8207-8214 (2016).

29. Krishnan, S., Ziegler, D., Arnaut, V., Martin, T. G., Kapsner, K., Henneberg, K., Bausch, A. R., Dietz, H. \& Simmel, F. C. Molecular transport through large-diameter DNA nanopores. Nat. Commun. 7, 12787 (2016).

30. Diederichs, T., Pugh, G., Dorey, A., Xing, Y., Burns, J. R., Nguyen, Q. H., Tornow, M., Tampé, R. \& Howorka, S. Synthetic protein-conductive membrane nanopores built with DNA. Nat. Commun. 10, :5018 (2019).

31. Thomsen, R. P., Malle, M. G., Okholm, A. H., Krishnan, S., Bohr, S. S., Sorensen, R. S., Ries, O., Vogel, S., Simmel, F. C., Hatzakis, N. S. \& Kjems, J. A large sizeselective DNA nanopore with sensing applications. Nat. Commun. 10, 5655 (2019).

32. Chidchob, P., Offenbartl-Stiegert, D., McCarthy, D., Luo, X., Li, J. N., Howorka, S. \& Sleiman, H. F. Spatial presentation of cholesterol units on a DNA cube as a determinant of membrane protein-mimicking functions. J. Am. Chem. Soc. 141, 11001108 (2019).

33. Mathieu, F., Liao, S., Kopatsch, J., Wang, T., Mao, C. \& Seeman, N. C. Six-helix bundles designed from DNA. Nano Lett. 5, 661-665 (2005).

34. Sacca, B. \& Niemeyer, C. M. DNA origami: The art of folding DNA. Angew. Chem. Int. Ed. 51, 58-66 (2012).

35. Langecker, M., Arnaut, V., List, J. \& Simmel, F. C. DNA nanostructures interacting with lipid bilayer membranes. Acc Chem Res 47, 1807-1815 (2014).

36. Ohmann, A., Gopfrich, K., Joshi, H., Thompson, R. F., Sobota, D., Ranson, N. A., Aksimentiev, A. \& Keyser, U. F. Controlling aggregation of cholesterol-modified DNA nanostructures. Nucleic Acids Res. 47, 11441-11451 (2019).

37. Rothemund, P. W. Folding DNA to create nanoscale shapes and patterns. Nature 440, 297-302 (2006).

38. Seeman, N. C. \& Sleiman, H. F. DNA nanotechnology. Nat. Rev. Mater. 3, 17068 (2017).

39. Hong, F., Zhang, F., Liu, Y. \& Yan, H. DNA origami: Scaffolds for creating higher order structures. Chem. Rev. 117, 12584-12640 (2017).

40. Praetorius, F., Kick, B., Behler, K. L., Honemann, M. N., Weuster-Botz, D. \& Dietz, H. Biotechnological mass production of DNA origami. Nature 552, 84-87 (2017).

41. Pugh, G. C., Burns, J. R. \& Howorka, S. Comparing proteins and nucleic acids for next-generation biomolecular engineering. Nat. Rev. Chem. 2, 113-130 (2018).

42. Litvinchuk, S., Tanaka, H., Miyatake, T., Pasini, D., Tanaka, T., Bollot, G., Mareda, J. \& Matile, S. Synthetic pores with reactive signal amplifiers as artificial tongues. Nat Mater 6, 576-580 (2007).

43. Sprengel, A., Lill, P., Stegemann, P., Bravo-Rodriguez, K., Schoneweiss, E. C., Merdanovic, M., Gudnason, D., Aznauryan, M., Gamrad, L., Barcikowski, S., Sanchez-Garcia, E., Birkedal, V., Gatsogiannis, C., Ehrmann, M. \& Sacca, B. Tailored protein encapsulation into a DNA host using geometrically organized supramolecular interactions. Nat. Commun. 8, 14472 (2017).

44. Bae, W., Kocabey, S. \& Liedl, T. DNA nanostructures in vitro, in vivo and on membranes. Nano Today 26, 98-107 (2019).

45. Burns, J. R. \& Howorka, S. Structural and functional stability of DNA nanopores in biological media. Nanomaterials 9, 490 (2019).

46. Burns, J. R. \& Howorka, S. Defined bilayer interactions of DNA nanopores revealed with a nuclease-based nanoprobe strategy. ACS Nano 12, 3263-3271 (2018). 
47. Burns, J. R., Göpfrich, K., Wood, J. W., Thacker, V. V., Stulz, E., Keyser, U. F. \& Howorka, S. Lipid bilayer-spanning DNA nanopores with a bifunctional porphyrin anchor. Angew. Chem. Int. Ed. 52, 12069-12072 (2013).

48. Burns, J. R., Al-Juffali, N., Janes, S. M. \& Howorka, S. Membrane-spanning DNA nanopores with cytotoxic effect. Angew. Chem. Int. Ed. 53, 12466-12470 (2014).

49. Ducani, C., Kaul, C., Moche, M., Shih, W. M. \& Hogberg, B. Enzymatic production of 'monoclonal stoichiometric' single-stranded DNA oligonucleotides. Nat. Methods 10, 647-652 (2013).

50. Zhang, Z., Yang, Y., Pincet, F., M, C. L. \& Lin, C. Placing and shaping liposomes with reconfigurable DNA nanocages. Nat. Chem. 9, 653-659 (2017).

51. Kuzyk, A., Schreiber, R., Fan, Z., Pardatscher, G., Roller, E. M., Hogele, A., Simmel, F. C., Govorov, A. O. \& Liedl, T. DNA-based self-assembly of chiral plasmonic nanostructures with tailored optical response. Nature 483, 311-314 (2012).

52. Chen, J. H. \& Seeman, N. C. Synthesis from DNA of a molecule with the connectivity of a cube. Nature 350, 631-633 (1991).

53. Zhang, Y. W. \& Seeman, N. C. Construction of a DNA-truncated octahedron. J. Am. Chem. Soc. 116, 1661-1669 (1994).

54. Douglas, S. M., Marblestone, A. H., Teerapittayanon, S., Vazquez, A., Church, G. M. \& Shih, W. M. Rapid prototyping of 3d DNA-origami shapes with cadnano. Nucleic Acids Res. 37, 5001-5006 (2009).

55. Dietz, H., Douglas, S. M. \& Shih, W. M. Folding DNA into twisted and curved nanoscale shapes. Science 325, 725-730 (2009).

56. Castro, C. E., Kilchherr, F., Kim, D. N., Shiao, E. L., Wauer, T., Wortmann, P., Bathe, M. \& Dietz, H. A primer to scaffolded DNA origami. Nat. Methods 8, 221-229 (2011).

57. Messager, L., Kim, J., Burns, J. R., Cecchin, D., Hindley, J., Pyne, A., Gaitzsch, J., Battaglia, G. \& Howorka, S. Biomimetic hybrid nanocontainers of designed permeability. Angew Chem Int Ed 55, 11106-11109 (2016).

58. Gut, I. G. \& Beck, S. A procedure for selective DNA alkylation and detection by mass-spectrometry. Nucleic Acids Res. 23, 1367-1373 (1995).

59. Ohmann, A., Li, C. Y., Maffeo, C., Al Nahas, K., Baumann, K. N., Gopfrich, K., Yoo, J., Keyser, U. F. \& Aksimentiev, A. A synthetic enzyme built from DNA flips 10(7) lipids per second in biological membranes. Nat. Commun. 9, 2426 (2018).

60. Maingi, V., Burns, J. R., Uusitalo, J. J., Howorka, S., Marrink, S. J. \& Sansom, M. S. Stability and dynamics of membrane-spanning DNA nanopores. Nat. Commun. 8, 14784 (2017).

61. Liu, P., Zhao, Y., Liu, X., Sun, J., Xu, D., Li, Y., Li, Q., Wang, L., Yang, S., Fan, C. $\&$ Lin, J. Charge neutralization drives the shape reconfiguration of DNA nanotubes. Angew. Chem. Int. Ed. 57, 5418-5422 (2018).

62. Kim, D. N., Kilchherr, F., Dietz, H. \& Bathe, M. Quantitative prediction of 3d solution shape and flexibility of nucleic acid nanostructures. Nucleic Acids Res. 40, 2862-2868 (2012).

63. Bellot, G., McClintock, M. A., Lin, C. \& Shih, W. M. Recovery of intact DNA nanostructures after agarose gel-based separation. Nat. Methods 8, 192-194 (2011).

64. Stahl, E., Martin, T. G., Praetorius, F. \& Dietz, H. Facile and scalable preparation of pure and dense DNA origami solutions. Angew. Chem. Int. Ed. 53, 12735-12740 (2014).

65. Xing, S., Jiang, D., Li, F., Li, J., Li, Q., Huang, Q., Guo, L., Xia, J., Shi, J., Fan, C., Zhang, L. \& Wang, L. Constructing higher-order DNA nanoarchitectures with highly purified DNA nanocages. ACS Appl. Mater. Interfaces 7, 13174-13179 (2015). 
66. Shaw, A., Benson, E. \& Hogberg, B. Purification of functionalized DNA origami nanostructures. ACS Nano 9, 4968-4975 (2015).

67. Douglas, S. M., Dietz, H., Liedl, T., Hogberg, B., Graf, F. \& Shih, W. M. Selfassembly of DNA into nanoscale three-dimensional shapes. Nature 459, 414-418 (2009).

68. Bai, X. C., Martin, T. G., Scheres, S. H. \& Dietz, H. Cryo-em structure of a 3d DNAorigami object. Proc Natl Acad Sci US A 109, 20012-20017 (2012).

69. Schreiber, R., Do, J., Roller, E. M., Zhang, T., Schuller, V. J., Nickels, P. C., Feldmann, J. \& Liedl, T. Hierarchical assembly of metal nanoparticles, quantum dots and organic dyes using DNA origami scaffolds. Nat. Nanotechnol. 9, 74-78 (2014).

70. Endo, M. \& Sugiyama, H. Single-molecule imaging of dynamic motions of biomolecules in DNA origami nanostructures using high-speed atomic force microscopy. Acc Chem Res 47, 1645-1653 (2014).

71. Andersen, E. S., Dong, M., Nielsen, M. M., Jahn, K., Subramani, R., Mamdouh, W., Golas, M. M., Sander, B., Stark, H., Oliveira, C. L., Pedersen, J. S., Birkedal, V., Besenbacher, F., Gothelf, K. V. \& Kjems, J. Self-assembly of a nanoscale DNA box with a controllable lid. Nature 459, 73-76 (2009).

72. Wei, B., Dai, M. \& Yin, P. Complex shapes self-assembled from single-stranded DNA tiles. Nature 485, 623-626 (2012).

73. Beckwitt, E. C., Kong, M. \& Van Houten, B. Studying protein-DNA interactions using atomic force microscopy. Semin Cell Dev Biol 73, 220-230 (2018).

74. Raghavan, G., Hidaka, K., Sugiyama, H. \& Endo, M. Direct observation and analysis of the dynamics of the photoresponsive transcription factor gal4. Angew. Chem. Int. Ed. 58, 7626-7630 (2019).

75. Franquelim, H. G., Khmelinskaia, A., Sobczak, J. P., Dietz, H. \& Schwille, P. Membrane sculpting by curved DNA origami scaffolds. Nat. Commun. 9, 811 (2018).

76. Suzuki, Y., Endo, M. \& Sugiyama, H. Lipid-bilayer-assisted two-dimensional selfassembly of DNA origami nanostructures. Nat. Commun. 6, 8052 (2015).

77. Hansma, H. G. \& Laney, D. E. DNA binding to mica correlates with cationic radius: Assay by atomic force microscopy. Biophys. J. 70, 1933-1939 (1996).

78. Mitchell, N., Ebner, A., Hinterdorfer, P., Tampe, R. \& Howorka, S. Chemical tags mediate the self-assembly of DNA strands into supramolecular structures. Small 6, 1732-1735 (2010).

79. Pyne, A., Thompson, R., Leung, C., Roy, D. \& Hoogenboom, B. W. Single-molecule reconstruction of oligonucleotide secondary structure by atomic force microscopy. Small 10, 3257-3261 (2014).

80. Lyubchenko, Y. L., Shlyakhtenko, L. S. \& Gall, A. A. Atomic force microscopy imaging and probing of DNA, proteins, and protein DNA complexes: Silatrane surface chemistry. Methods Mol. Biol. 543, 337-351 (2009).

81. Arnott, P. M. \& Howorka, S. A temperature-gated nanovalve self-assembled from DNA to control molecular transport across membranes. ACS Nano 13, 3334-3340 (2019).

82. Goyal, P., Krasteva, P. V., Van Gerven, N., Gubellini, F., Van den Broeck, I., Troupiotis-Tsaïlaki, A., Jonckheere, W., Péhau-Arnaudet, G., Pinkner, J. S., Chapman, M. R., Hultgren, S. J., Howorka, S., Fronzes, R. \& Remaut, H. Structural and mechanistic insights into the bacterial amyloid secretion channel csgg. Nature 516, 250-253 (2014).

83. Jun, H., Zhang, F., Shepherd, T., Ratanalert, S., Qi, X., Yan, H. \& Bathe, M. Autonomously designed free-form 2d DNA origami. Sci Adv 5, eaav0655 (2019). 
84. Lacroix, A., Edwardson, T. G. W., Hancock, M. A., Dore, M. D. \& Sleiman, H. F. Development of DNA nanostructures for high-affinity binding to human serum albumin. J. Am. Chem. Soc. 139, 7355-7362 (2017).

85. Birkholz, O., Burns, J. R., Richter, C. P., Psathaki, O. E., Howorka, S. \& Piehler, J. Multi-functional DNA nanostructures that puncture and remodel lipid membranes into hybrid materials. Nat. Commun. 9, 1521 (2018).

86. Praetorius, F. \& Dietz, H. Self-assembly of genetically encoded DNA-protein hybrid nanoscale shapes. Science 355, eaam5488 (2017).

87. Fogarty, J. C., Arjunwadkar, M., Pandit, S. A. \& Pan, J. Atomically detailed lipid bilayer models for the interpretation of small angle neutron and x-ray scattering data. Biochim. Biophys. Acta 1848, 662-672 (2015).

88. Plesa, C., Kowalczyk, S. W., Zinsmeester, R., Grosberg, A. Y., Rabin, Y. \& Dekker, C. Fast translocation of proteins through solid state nanopores. Nano Lett. 13, 658663 (2013).

89. Baaken, G., Ankri, N., Schuler, A. K., Ruhe, J. \& Behrends, J. C. Nanopore-based single-molecule mass spectrometry on a lipid membrane microarray. ACS Nano $\mathbf{5}$, 8080-8088 (2011).

\section{FIGURE LEGENDS}

Fig. 1 | Schematic overview for the design, assembly and characterization of DNA nanopores. The key steps involved are exemplified using a small nanobarrel composed of a bundle of six interconnected DNA helices (blue).

Fig. 2 | Overview of several existing DNA nanopores. (a) Top and side views of DNA nanopores with increasing inner diameter from left to right, each blue cylinder represents a single DNA duplex. Nanobarrel-type DNA pores composed of four helix bundles $(4 \mathrm{HB})^{20}$ and six helix bundles $(6 \mathrm{HB})^{22-26}$ are built from equimolar component oligonucleotides. Larger DNA origami-based pores with fifty-four helix bundles $(54 \mathrm{HB})^{21}$ and seventy-two helix bundles $(72 \mathrm{HB})^{28,30}$ are constructed using a long scaffold strand and multiple shorter DNA staple strands. The number of helices does not directly relate to the size of the membranespanning channel as illustrated for a $2 \mathrm{~nm}$-wide lumen of the 54HB pore and a nominal $6 \times 6$ $\mathrm{nm}$ lumen of a 72HB pore. (b) Lipid anchors (purple) utilized to achieve membrane insertion include ethyl-phosphorothioate ${ }^{23}$, cholesterol $^{20-22}$, porphyrin ${ }^{19,47}$, and tocopherol ${ }^{29}$. (c) The choice of lipid anchor affects the interaction of the DNA pore with the surrounding bilayer membrane as shown for type I interactions with hydrophobic belts composed of multiple ethylphosphorothioate modifications ${ }^{23,60}$, and type II interactions with isolated cholesterol or other anchors such as porphyrins and tocophoerol ${ }^{22}$. (d) The hydrophobic belt or lipid anchors along the DNA pore can be positioned at the center ${ }^{23}$ or terminus of the membrane-spanning region ${ }^{47}$, or at the cap region of large DNA origami pores to protrude into the lipid bilayer ${ }^{21}$.

Fig. 3 DNA nanopores designed via the nanobarrel or DNA origami method. Example of the nanobarrel (a-c) and DNA origami method (d-f). (a) Side and top view of a 6HB where each cylinder represents a single duplex numbered 1-6 ( ref $\left.^{22}\right)$. (b) 2D map of the $6 \mathrm{HB}$ showing the strand connectivity of the 6 component oligonucleotides (various colors), the 5 ' terminus is represented by a square, and the 3 ' terminus with a triangle. (c) CanDo simulation of the $6 \mathrm{HB}$ nanobarrel pore in top and side views, color scale indicates the flexibility shown as the rootmean-square fluctuations in $\mathrm{nm}$. (d) Side and top view of large DNA origami-based nanopore $72 \mathrm{HB}^{28,30}$, each cylinder represents a single duplex numbered 0-71. (e) 2D map and magnified view of the $72 \mathrm{HB}$ pore showing the connectivity of the scaffold strand (blue) and hundreds of 
staple strands (red). (f) CanDo simulation of the 72HB nanopore top and side views, the color scale indicates the flexibility shown as the root-mean-square fluctuations in $\mathrm{nm}$.

Fig. 4 | Nanobarrel strand maps showing the connectivity of various designs for nanobarrel-type DNA pores. (a) In this 6HB design, the duplexes are linked via terminal crossovers, and the structure is assembled from 6 component strands ${ }^{22}$. (b) The 4HB design features duplexes linked via single crossovers throughout the nanostructure, assembled from 8 component strands ${ }^{20}$. (c) In a related 6HB design, six duplexes are linked via double crossovers and terminal crossovers. The structure is assembled from 8 component strands ${ }^{48}$. (d) Wireframe-based DNA cube with 6 component strands ${ }^{32}$. The 5' and 3' DNA termini in all designs are represented by a square and triangle, respectively.

Fig. 5 | Screenshots taken from CaDNAno showing the two lattice networks. (a) Honeycomb lattice where the duplexes are organized in a hexagonal arrangement, each duplex can form cross-overs with three neighboring helices. (b) Square lattice where the duplexes are organized in a tightly packed arrangement, each duplex can form crossovers with four neighboring helices leading to a more tightly packed origami structure.

Fig. 6 | The 72HB DNA origami nanopore designed using the CaDNAno interface with Maya 2015. The "Slice Panel" (top left) shows a bird's eye view of each duplex, the "Path Panel" (bottom left) shows the 2D map of the scaffold and staple strands, and the "Render Panel" (right) shows the $3 \mathrm{D}$ representation of the nanostructure (in this case the $72 \mathrm{HB}^{30}$ ).

Fig. 7 | Using CaDNAno to generate the DNA origami structure and staple sequences. (a) "Path Panel" view of 6 separate scaffold strands with the desired dimensions. (b) Corresponding scaffold strands joined together via terminal and internal crossovers. (c) 2D strand map containing the staple strands (various colors) generated by selecting "AutoStaple", the thicker staples indicate a violation of the ideal parameters for staple length. (d) The staples can be automatically chopped into suitable lengths using the "AutoBreak" function. (e) Dialog boxes for the "AutoBreak" and "Sequence" functions. (f) Comma separated variable (.csv) file generated by CaDNAno when imported into Excel, the file contains the name of each staple as defined its termini positions, its sequence in the $5^{\prime} \rightarrow 3^{\prime}$ direction, and the staples defined "Color".

Fig. 8 | Gel electrophoretic characterization of DNA nanopores. (a) Agarose gel and (b) PAGE images of the $6 \mathrm{HB}$ pores. Lane 1, 6HB-0C carrying no cholesterol anchors; lane 2, $6 \mathrm{HB}-$ $1 \mathrm{C}$ with one cholesterol anchor; lane 3,6HB-3C with three cholesterols anchors. (c) Agarose gel image of DNA origami $72 \mathrm{HB}$ constructs. Lane 1, staple strands; lane 2, scaffold strand; lane 3, 72HB-0C with no cholesterol anchors; lane 4, 72HB-24C carrying 24 cholesterol anchors. The position and kilo bp length of the dsDNA markers is annotated on the left of each gel.

Fig. 9 | Representative TEM images of nanobarrel and DNA origami nanopores and their interaction with lipid membranes. (a) A $6 \mathrm{HB}$ nanobarrel pore without cholesterol anchors ${ }^{60}$ oriented either upright or along the surface of the TEM grid. (b) Magnification of a. (c) The 72HB-24C DNA origami nanopore ${ }^{30}$ aligned parallel to the TEM grid. (d) Four 72HB-24C nanopores inserted into a single SUV. All scale bars $25 \mathrm{~nm}$.

Fig. 10 | Electrophoretic quantification of DNA nanopore binding to SUVs using a gelshift assay. (a) $2 \%(\mathrm{wt} / \mathrm{vol})$ agarose gel-binding analysis of $6 \mathrm{HB}-2 \mathrm{C}^{60}$ with SUVs, and control 
samples: 6HB-0C with SUVs, and SUVs only. The boxes on the gel image represent ImageJ selections using the "Rectangular Selection" tool. The blue box around the unbound 6HB-2C band was used to determine the band intensity $I_{6 H B}$ which was corrected for the background of

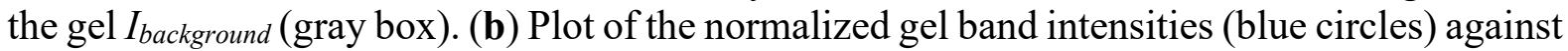
SUV concentration with a Michaelis-Menten line-of-best-fit (blue line), the normalized intensities were calculated by $1-\left(I_{6 H B}-I_{\text {background }}\right)^{25}$.

Fig. 11 | Single-channel current analysis of DNA nanopores using planar lipid bilayer recordings. (a) Schematic illustration of $6 \mathrm{HB}$ DNA nanopore ${ }^{22}$ (blue) embedded in lipid bilayer (dark gray) spread over a MECA16 chip microcavity (gold) ${ }^{89}$. (b) The MECA16 chip. (c) Current recordings of an empty cavity (left), a cavity with a DPhPC planar lipid bilayer spanning the cavity (middle), and a membrane-spanning DNA nanopore (bottom).

Fig. 12 Extracting data from raw current traces. Example data of $6 \mathrm{HB}$ pore $\mathrm{e}^{22}$ and a DNA-nanopore constructed with DNA origami ${ }^{30}$. (a) A raw trace at $-100 \mathrm{mV}$ for the $6 \mathrm{HB}-$ nanopore (left). At high voltages, prominent sub-conductance states are observed and can be quantified by producing an all-point histogram (right). From the histogram, the average current and conductance of each state can be obtained by Gaussian fitting. (b) A trace of the $6 \mathrm{HB}$ pore showing $10 \mathrm{mV}$ voltage steps from $-150 \mathrm{mV}$ to $+150 \mathrm{mV}$ (left). Average currents at each step can be plotted in an $I V$ curve (right), the gradient of which can be used to describe the unitary conductance $(Q)$ of the pore. (c) Single-channel search using the Clampfit software (left) showing blockade events of a DNA origami nanopore ${ }^{30}$. Each spike is caused by translocation of individual molecules of the protein trypsin. Data extracted from the single-channel search can be presented on a percent blockage plotted against dwell time graph (right).

Fig. 13 Example traces of the dye flux assay. The example assay was carried out using the 6HB-3C pore $^{22}$ which demonstrates charge-specific dye transport. Sulforhodamine B (SRB, red) contains two negative charges and one positive charge (net charge of minus one) and shows an increase in fluorescence signal indicating successful dye transport. Carboxyfluorescein (CF, blue) contains three negative charges (net charge of minus three) and shows no change in fluorescence signal indicating $\mathrm{CF}$ cannot translocate through the $6 \mathrm{HB}$ pore under these conditions. 